\title{
WHY IS
}

\section{THE HONG KONG HOUSING MARKET UNAFFORDABLE? \\ SOME STYLIZED FACTS \\ AND ESTIMATIONS}

\author{
Charles Ka Yui Leung \\ Joe Cho Yiu Ng \\ Edward Chi Ho Tang
}

March 2020

The Institute of Social and Economic Research

Osaka University

6-1 Mihogaoka, Ibaraki, Osaka 567-0047, Japan 


\title{
Why is the Hong Kong housing market unaffordable? Some stylized facts and estimations ${ }^{\Lambda}$
}

\author{
Charles Ka Yui LEUNG, City University of Hong Kong \\ Joe Cho Yiu NG, City University of Hong Kong \\ Edward Chi Ho TANG, Hong Kong Shue Yan University ${ }^{\Re}$
}

This version: March 2020

\begin{abstract}
The house price in Hong Kong is well-known to be "unaffordable." This paper argues that the commonly used house price-to-income ratio may be misleading in an economy with almost half of the population living in either public rental housing or subsidized ownership. Moreover, we re-focus on the relationships between economic fundamentals and the housing market of Hong Kong. While the aggregate GDP, population, longevity continues to grow, the real wage and household income fall behind. The trend component of the real GDP growth suffers a permanent downward shift after the first quarter of 1989 (a "political scar"). The trend component of real wage growth is close to zero, and the counterpart of real consumption and real investment decline steadily. Meanwhile, the trend component of the real housing rent and price display patterns that decouple from the macroeconomic variables. We also discuss the directions for future research.
\end{abstract}

Keywords: housing demand, migration, structural break, time series decomposition, wage index and household income

JEL Classification Numbers: E20, J01, R00

\footnotetext{
${ }^{\Lambda}$ Acknowledgment: We are grateful to Alain Bertaud, Nan-Kuang Chen, Bob Edelstein, Eric Hanushek, Fred Kwan, Tommy Leung, Steve Malpezzi, Shane Su, Byron Tsang, Isabel Yan, Matthew Yiu, anonymous referees, seminar participants of the National Taiwan University for many helpful discussion, and City University of Hong Kong (through the Internal Grant No. 7005001) and Hong Kong Shue Yan University for financial support. Part of the research is conducted when Leung visits the Hoover Institution; Ng visits the Virginia Tech through a Junior Fulbright Scholarship. The hospitality of these institutions is gratefully acknowledged. Part of the work described in this paper was supported by a grant from the Research Grants Council of the Hong Kong Special Administrative Region, China (Project No.: UGC/FDS15/B01/18). The usual disclaimer applies.

${ }^{\Re}$ Correspondence: Leung and Ng, Department of Economics and Finance, City University of Hong Kong, Kowloon Tong, Hong Kong, kycleung@cityu.edu.hk, joecyng-c@my.cityu.edu.hk; Tang, Department of Economics and Finance, Hong Kong Shue Yan University, North Point, Hong Kong, chtang@hksyu.edu.
} 


\section{Introduction}

Housing affordability has become a global concern. According to McKinsey (2017), “One feeling unites billions of people in cities around the world: a sense of sticker shock whenever they attempt to find a new home. From London to Lagos, housing costs are creating financial stress for a large share of the world's urban residents.” Some authors claim that Hong Kong performs worst in providing affordable housing among the global cities. For instance, according to Demographia (2019), “The 29 severely unaffordable major housing markets are shown in Table 7. Hong Kong has a Median Multiple of 20.9, the least affordable Median Multiple yet recorded. For the ninth year in a row, Hong Kong has the worst housing affordability in the Demographia International Housing Affordability Survey...”

Motivated by these observations, this paper addresses the following questions: Is Hong Kong housing that unaffordable? Why is it so prohibitive? What can other places learn from the Hong Kong experience? To make this paper as accessible as possible, we first present some stylized facts graphically. We provide explanations and interpretations of those graphs. We will also provide some statistical analysis when necessary.

This paper builds on several strands of the literature. First, there is an effort to compare and contrast the institutions and performance across different housing markets. ${ }^{1}$ Second, many works of literature have studied how the housing market is related to the macroeconomy. ${ }^{2}$ Third, there is relatively small literature that focuses on the Hong Kong real estate markets. ${ }^{3}$ Fourth, since most residents in Hong Kong are ethnic Chinese and at the same time being exposed to the global culture, this paper is also related to the literature on the Chinese housing market. ${ }^{4}$ Fifth, the trade conflict

\footnotetext{
${ }^{1}$ It is beyond the scope of this paper to review the literature. Among others, see Bardhan et al. (2012), Ben-Shafar et al. (2008), Bertaud (2018), Hårsman and Quigley (1991), Mera and Renaud (2000), Renaud et al. (2016).

${ }^{2}$ It is beyond the scope of this paper to review the literature. Among others, see Case and Quigley (2008), Chang et al. (2012, 2013, 2016), Chen and Leung (2008), Favilukis et al. (2017), Garriga et al. (2017), Jin et al. (2012), Kan et al. (2004), Kiyotaki and Moore (1997), Leung (1999, 2001, 2003), Leung and Chen (2006), Leung and Teo (2011), Leung and Tse (2017), Lin et al. (2004), Malpezzi (2017), Tse and Leung (2002). For a review of the literature, see Davis and Van Nieuwerburgh (2014), Leung (2004, 2017), Leung and Chen (2017), Leung and Ng (2019), Piazzesi and Schneider (2016). ${ }^{3}$ It is beyond the scope of this paper to review the literature. Among others, see Cheung et al. (2017), Chong and Yiu (2019), Chow et al. (2002), Funke and Paetz (2018), Huang et al. (2018), Kwan et al. (2015), Leung and So (2004), Leung and Sung (2006), Leung and Tang (2012, 2015a, b), Leung and Wong (2004), Leung et al. (2013, 2014, 2015, 2019), Oxfam (2018), Sung et al. (2015), Tang (2017, 2019), Wong (1998), Wong et al. (2018), Wu et al. (2017).

${ }^{4}$ It is beyond the scope of this paper to review the literature. Among others, see Chen and Wen (2016),
} 
between China and the United States has non-trivial consequences to other countries, as some authors have found preliminary evidence on that. ${ }^{5}$ Hong Kong, being a part of China and intermediates many goods trade as well as financial transactions for China, is affected. It also sheds light on the "spillover effects” of the China-USA trade conflicts. And while the Hong Kong housing market has been discussed previously (Leung and Tang, 2012, 2015a, b, and the reference therein), this paper provides some updated analysis on the housing affordability and conduct a time-series decomposition of the key macro variables. This paper intends to be accessible to a broad audience in Asian and other countries, as economic lessons are typically general. Therefore, we present our results graphically.

The structure of this paper is straightforward. We present some stylized facts of the Hong Kong housing market and the macroeconomy. We then decompose the time series of the main variables of the housing market and the macroeconomy. The evidence suggests that the "unaffordability" of the housing market may have its roots in some long term trend. We provide some simple thoughts in the concluding section.

\section{Hong Kong Housing Market and the Macroeconomy}

As an international financial center, Hong Kong is mentioned in global media from time to time. With a fixed boundary and a fixed exchange rate with the United States, Hong Kong has been able to attract much non-local investment in its real estate sector. ${ }^{6}$ Therefore, the housing unaffordability concerns by Demographia and other organizations deserve serious attention. We begin our discussion with the house price. Unless specified otherwise, our data comes from the Hong Kong government official website. ${ }^{7}$ Figure 1 a shows that the real house price in 2018, i.e., the house price after removing the inflation factor, is $400 \%$ of the 1979 level. It also shows that the house

Chen et al. (2017), Deng et al. (2017), Huang et al. (2015), Leung and Wang (2007), Leung et al. (2011), Wu et al. (2012, 2016).

${ }^{5}$ The literature related to this recent trade war is growing. Among others, see Abiad et al. (2018), Amiti et al. (2019), Guo et al. (2018), Mandelman and Waddle (2019), Tham et al. (2019).

${ }^{6}$ Notice that the United States follows (approximately) a version of the Taylor rule, which is an interest rate rule (Koenig et al., 2012). Since Hong Kong maintains a fixed exchange rate with the U.S., Hong Kong nominal interest rate follows the U.S. counterpart. See Chang et al. (2012, 2013, 2016) for more discussion.

${ }^{7}$ The government official website for data is https://www.censtatd.gov.hk/home.html. 
price and stock price, while both have an upward trend, do not always move together. ${ }^{8}$ Also, some authors suggest that, since the Hong Kong dollar exchange rate is linked with the U.S., the U.S. monetary policy will dictate the Hong Kong house price. Figure 1b shows that while the U.S. interest rate influences the Hong Kong real housing price growth rate, it is not the only factor.

Moreover, Figure 1c suggests that the house price increases faster than the wage, as the house price-to-wage ratio increases from 100 (1982 level) to about 270 (2018 level). To facilitate the comparison, we also plot the same ratio for the United States. The U.S. counterpart increases from 100 to 160 during the same period. These figures confirm the Demographia assertion that the housing affordability in Hong Kong has indeed deteriorated.

(Figure 1 about here)

However, those figures overlook an essential feature of the Hong Kong housing market; namely, a significant number of households live in need-based public rental housing, and hence they are somehow "protected" from the appreciation of the house price. ${ }^{9}$ To illustrate the point that the size of the public rental housing matters, let us consider an economy with only three agents, A, B, and C. The agents are labeled in such a way that the income of agent $\mathrm{A}$ is lower than agent $\mathrm{B}$, and the income of agent B is, in turn, more moderate than agent C. In this artificial economy, the median agent is B. Hence, agent B's house price-to-income ratio is the economy's median house price-to-income ratio. Now assume that agent A instead lives in public housing, whose rent is subsidized by the government. The private housing market consists of only two agents, $\mathrm{B}$, and $\mathrm{C}$. The median house price-to-income ratio of the economy becomes the average of the house price-to-income ratio of agent B and C. In other words, the existence of public housing changes the median house price-toincome ratio in the private housing market.

Let us consider another economy with five agents, A, B, C, D, and E. As in the previous example, the agents are arranged so that the income of agent $\mathrm{A}$ is lower than that of agent B, and so on. Agent $\mathrm{E}$ has the highest income. In a scenario with no government intervention, the median agent is agent $\mathrm{C}$. The house price-to-income

\footnotetext{
${ }^{8}$ For the co-movement between the stock price and housing price, see Leung (2007), Leung and Teo (2011) for theoretical analysis, Chen and Shen (2005) for the case of Taiwan, and Chang et al. (2013), Kwan et al. (2015) for the case of Hong Kong.

${ }^{9}$ For more details, see https://www.housingauthority.gov.hk/en/flat-application
} 
ratio of agent $C$ is the economy's median house price-to-income ratio. Now the government provides not only public rental housing to agent A but also subsidized ownership to agent $B$. In this new scenario, only agents $C$, D, and $E$ face the private housing market, and the (new) median agent in the private housing market is agent D. And if we want to measure the house price-to-income ratio in the private housing market, we should measure the ratio of agent $\mathrm{D}$, not agent $\mathrm{C}$. In other words, in a world without any government intervention, the median agent in the income distribution and the private housing market would be the same person. However, when the government intervenes through public rental housing or subsidized ownership, the median agent in the income distribution will no longer coincide with the median agent in the private housing market. Hence, if the government participation in the housing market is sizable, we expect the distortion of using the median house price-to-income ratio would be sizable as well.

In Hong Kong, government involvement in the housing market is indeed massive. The public rental housing project began in 1953 and since then grows with the economy (Smart, 2006; Yeung and Wong, 2003). ${ }^{10}$ Figure 2a shows the number of households lives in different types of housing: public rental, subsidized ownership, and private. Figure $2 \mathrm{~b}$ shows the number of housing units for each kind of shelter. While the growth rate of public rental housing and occupants seem to be lower than the private housing in recent years, the public rental sector still accounts for roughly one-third of the housing market. The subsidized ownership approximately accounts for another oneseventh of the housing market. Together, it means that the private housing market (rental plus ownership) accounts for roughly half of the population.

Furthermore, Figure 2c shows that public housing rent is significantly below the market counterpart. ${ }^{11}$ Since the rent in public housing is significantly below the market

\footnotetext{
${ }^{10}$ Among others, see Gong and Leung (2019), Leung et al. (2012), Leung and Tang (2015) for more discussion on the public housing allocation.

${ }^{11}$ Since the public rental housing is highly subsidized, there is rationing. To be eligible for applying for public housing, the family should satisfy the income and asset test prescribed by the Housing Authority. It typically takes several years for a household to receive a public housing unit. The official account of the rent policy in those public rental units can be downloaded from the government website: https://www.housingauthority.gov.hk/en/common/pdf/about-us/policyfocus/policies-on-public-housing/B01/B01.pdf In October 2017, the Housing Authority tightened "Well-off Tenants Policies.” Households whose income exceeds five times the current income limits (PRHILS) or whose total household net asset value exceeds 100 times PRHILs should vacate the flats. For an earlier discussion, see Wong (1998) and the reference therein.
} 
and adjusts slower than the market, it appears to be safe to conclude that up to a third of the population is shielded from the housing market fluctuations, and they tend to be the lower-income households. Since public housing shelter in such a scale is absent in most countries, it may suggest that merely comparing the Hong Kong house price-toincome ratio, or similar metrics, with other countries, may not be as informative as previously thought.

(Figure 2 about here)

Many authors compare the housing market of Hong Kong with Singapore. While the two economies have many similarities, we caution a direct comparison of the two housing markets. For instance, while nearly $90 \%$ of the population in Singapore live in "public housing," most of those public housing units are "subsidized ownership." Those Singaporean owner-occupiers would need to bear the capital risk should they need to re-sell the housing units in the market. The portion of the population living in pure public rental housing is less than $10 \%$ of the whole population (Deng et al., 2014). It is very different from the case of Hong Kong.

Besides, a higher level of house price-to-income ratio may be driven by a house price level which is too high, or an income level which is too low, or both. We present a series of graphs that may give us some hints. Figure 3a shows that the real GDP per capita does increase over time. However, the wage in Hong Kong does not grow as fast. To facilitate the comparison, we plot the ratio of the official wage index relative to the real GDP per capita and rebase that as unity in 1982. Leung and Tang (2015) show that if (1) the aggregate production is in a Cobb-Douglas form, as many macroeconomics textbooks suggest, and (2) both the product markets and input markets are perfectly competitive, then the ratio of wage relative to GDP per capita should be a constant. This result holds even when the aggregate productivity fluctuates. This analytical result gives us a handy benchmark.

Figure $3 \mathrm{~b}$ shows that this is not the case. The ratio drops from unity to around 0.6 over the years, which significantly and persistently departs from the theoretical benchmark. There are different possible interpretations. For instance, some suggest that alternative contractual arrangements are now available in Hong Kong, and hence the wage index has ceased to be an informative indicator. OECD (2016) recognizes that in Europe, at least half of the employees benefit from various kinds of flexible working 
arrangements, including working part-time, working at home, etc. The presence of this arrangement could affect the information contents of the wage index. Also, the wage index concerns an individual, while in practice, there are many multi-member households. There is evidence that in multi-member families, some members may specialize in market production while other members may specialize in household production (Becker, 1994; Erosa et al. 2017). In that case, household income-based measures may be more relevant than the individual-based wage index.

Figure 3c presents both the ratio of median household income relative to the GDP per capita and the ratio of wage index relative to the GDP per capita. Again, we normalize both ratios as unity at the initial period that we can access the relevant data, which is 1999. Several patterns are apparent. First, relative to the GDP per capita, both the median household income and the wage index roughly declines at the same speed as the wage index between 1999 to 2006. In other words, the median household income series and the wage index follow the same downward trend during the period 1999 to 2006, and hence our previous result is robust in this sense. After the global financial crisis (GFC) began, the median household income almost stays constant, while the wage index continues to decline from roughly $85 \%$ to $75 \%$ of the per capita GDP. The difference between the individual-based wage index and the household income is consistent with the "income insurance" view of marriage. When a husband, for instance, loses his job in a recession, the labor supply of his wife tends to increase and hence stabilizes the household income (e.g., Bredtmann et al., 2018; Bryan and Longhi, 2018, Greenwood et al., 2017, and the reference therein).

There are different possible explanations of the decline of wages relative to the per capita GDP. Recall that the ratio is supposed to be a constant under perfect competition. Hence, the observed departure suggests a violation of the perfectly competitive assumption, which is consistent with some earlier studies. For instance, Lubik (2012) proposes a search-and-match model to account for the Hong Kong labor market dynamics, and he structurally estimates his model with the Bayesian method. He finds that the bargaining power of the employees is minimal.

Alternatively, it is also consistent with emerging literature on the declining labor share of GDP (Dao et al., 2017; Gutierrez, 2017; Karabarbounis and Neiman, 2013). Autor et al. (2017) suggest that it is possible that while the labor share of output among most firms is high, some "superstar firms," which are large and growing, could bring the aggregate labor share to decline over time. Notice that if the labor share of GDP 
shrinks over time, the wage may grow slower than the per capita GDP. Since a full account of this issue will demand another paper, we will return to the housing market of Hong Kong.

(Figure 3 about here)

Taking the high price of housing as given, we now ask what are the driving forces behind. Again, we address this question through a series of graphs. We have already shown that the real GDP per capita of Hong Kong grows over time (Figure 3a). Also, Figure 4a shows that both the population and life expectancy of Hong Kong increase over time. While the fertility of Hong Kong is below the replacement level, there is a continuous flow of immigrants coming to Hong Kong, especially from Mainland China. With more people, and on average longer lives and higher income per person, it is not surprising that the housing demand increase over time. Besides, Figure 4b shows the composition of Hong Kong households in terms of the size of the family. The proportion of one-person and two-person households has increased over time. It means that even if the total population is constant, there is a higher demand for housing units. Thus, with growing income, growing population, lengthening the longevity of life, shrinking the household size, the aggregate housing demand of Hong Kong increases over time.

(Figure 4 about here)

The housing supply of Hong Kong is affected by different factors and has been discussed recently by Leung et al. (2020), we provide only a simple overview here. Figure 4c compares the population densities across countries and regions and demonstrates that the population density of Hong Kong may indeed be high. If we take into considerations that Hong Kong is hilly and a substantial amount of land are not suitable for high-rise building, the population density is even higher. It is not uncommon to see residential buildings with more than 30 floors. Thus, it is not surprising that the house price of Hong Kong would be high. Yet the housing supply does not increase enough to meet the growing demand. Figure $4 \mathrm{~d}$ shows that the new housing supply of Hong Kong, adjusted for the existing stock, decreases over time and is below $2 \%$ since 2005, while the real house price displays a clear upward trend. Notice that the official data provides only the gross new supply, not the net new supply. It means that while there may be, say, 20,000 new units being supplied in the market in a 
particular year, there may be 5,000 units being demolished in the same year for the urban re-development purposes. Hence, the net new supply could be far less than the gross counterpart.

Why did not the housing supply increase as the house price increases? A popular and convincing reason is that the housing supply is artificially constrained by regulation under different justifications. Many studies have confirmed that as a nearly universal reason for limited housing supply. ${ }^{12}$ In Hong Kong, the density of residential development is guided by the plot ratio. It compares the gross floor area of a building and the site's area. ${ }^{13}$ While the institution of the plot ratio may enhance the environmentally friendly dimension of the city, it restricts the gross floor area to be completed in a project. Hence, it may reduce the incentives for developers to redevelop some areas, which indirectly limits the new housing supply. Such distortion in housing supply can lead to severe economic consequences. ${ }^{14}$

The institutions of Hong Kong may contribute to this housing supply shortage problem. Unlike many countries with similar income levels per capita, land ownership in Hong Kong is public. Strictly speaking, the "land sale" in Hong Kong is the sale of the right of usage of a particular piece of land during a specific period. Thus, the official name of the "land sale revenue" is "land premium." An alternative way for the developers to obtain land is to apply for changes in land use. Usually, it involves a shift of agricultural land to residential land, and the developer needs to pay a mutually agreed price to the government. The Government can also invoke the Lands Resumption Ordinance to resume three types of private land for developing public housing and Starter Homes. ${ }^{15}$ Hence, the Hong Kong government almost control the land supply of Hong Kong and influence the land price. Leung and Tang (2015b), among others, promote the view that the Hong Kong government effectively operates as a durable goods monopoly with limited supply, dynamically tradeoffs the quantity of land and revenue that can be generated from the land sale. Figure 5a demonstrates the increasing tendency for the Hong Kong government to depend on real-estate related tax. Here we only include the revenue from land sale ("land premium") and property tax ("rate"). ${ }^{16}$

\footnotetext{
${ }^{12}$ Among others, see Glaeser and Gyourko (2018), Green et al. (2005), Saiz (2010), and the reference therein.

${ }^{13}$ For details, see https://www.pland.gov.hk/pland_en/tech_doc/hkpsg/full/pdf/ch2.pdf

${ }^{14}$ Among others, see Herkenhoff et al. (2017) for a structural estimation for the U.S. case.

${ }^{15}$ For details, please visit https://www.policyaddress.gov.hk/2019/eng/highlights.html

${ }^{16}$ The Hong Kong government also collects "stamp duties," which are transaction taxes in the stock
} 
Between 1990 and 1996, the proportion of real estate-related tax constitutes no more than $15 \%$ of the total revenue. The ratio experiences ups and downs since the 1997 handover to China and reaches a historical high of 30\% in 2018. Figure 5b provides another illustration of the Hong Kong government's real estate-dependency. It shows that both the fiscal-GDP and hypothetical fiscal surplus-GDP ratio of Hong Kong over time, where the hypothetical fiscal surplus is the official budgetary surplus minus the land sale revenue. It is clear that if the land sale revenue were zero, the Hong Kong government has been in deficit since 2008, when the Global Financial Crisis (GFC) broke out.

Figure 5c shows that, while the Hong Kong government is increasingly dependent on land sale and other real estate-related revenue on the income side, its expenditure on housing, include the provision of public housing, has decreased over time. The share of housing-related spending is about $14 \%$ of the total government expenditure in 1989 and falls since then. It rebounded to its peak around 15\% near 2000 and touched down to around 7\% since 2004. In light of these graphs, it may not be surprising that the queue for public housing has extended, and the shelter in Hong Kong becomes increasingly "unaffordable" in recent years.

(Figure 5 about here)

We should stress that the dependence of real estate tax revenue needs not to be undesirable. For instance, Henry George argues that the government should use land tax to replace other forms of taxation. According to George (1879, chapter 22), as "population grows and technology advances, land values rise. This steady increase leads to speculation, as future increases are anticipated. Land values are carried beyond the point at which labor and capital would receive their customary returns. Production, therefore, begins to stop.”

Furthermore, George (1879, chapter 32) argues that "to formally confiscate all land would involve a needless shock, and would require a needless extension of government. Both can be avoided... It is not necessary to confiscate land-only to confiscate rent.... Land values increase as population grows and progress advances.... 
Taxation of rent would increase as we abolish other taxes.... To abolish all taxesexcept on land values.” While this idea seems radical, it has been widely discussed by economists (e.g., Behrens et al., 2015; Kawano, 2014; Newton, 1971; Stigler, 1974). On the other hand, we are not aware of any severe calibration work to examine the optimality or practicality of the Henry George theorem. We recommend future research to take up this challenge, which may enhance our discussion of the policy design for Hong Kong or economies in similar conditions.

Another factor that may contribute to the apparent "housing shortage" in Hong Kong is the change in immigration. Interestingly, the Hong Kong government does not collect the immigrant data, or they have not made it publicly accessible. We have access to the data for the so-called "one-way permit," which keeps track of the number of immigrants from Mainland China to Hong Kong. Also, there is the Admission Scheme for Mainland Talents and Professionals (ASMTP), which allows Mainland Chinese with unique talents to migrate to Hong Kong. ${ }^{17}$ We have no information about how many people from other places move to Hong Kong, or how many moves from Hong Kong to other countries.

Several remarks regarding this one-way permit system are in order. First, the one-way permits are issued by the Mainland China government, and hence the Hong Kong government cannot select who would be granted access to Hong Kong. Second, since we do not have access to the out-migrant data, we are unable to distinguish those Mainland Chinese immigrants permanently stay in Hong Kong and those who ultimately migrate to other countries through Hong Kong. The daily quota of the oneway permit has also changed over time. It increases from 75 to 105 in 1994 and further to 150 in 1995. The age composition of Chinese immigrants to Hong Kong is displayed in Figure 6. There exhibits a clear trend that the proportion of young Mainland immigrants decreases while the percentage of senior adult increases, especially in recent years.

These changes may have significant consequences. First, since the Hong Kong government cannot select the immigrants, and hence skill-mismatch is likely, meaning that those who immigrate to Hong Kong might not have the skill set that Hong Kong's economy demands. Since it is easier to train young people than senior adults, the

\footnotetext{
${ }^{17}$ For details, see https://www.immd.gov.hk/eng/faq/admission-scheme-mainland-talentsprofessionals.html
} 
composition change may have implications for the quality of the workforce in Hong Kong. Second, the literature suggests that other things being equal, immigrant workers are paid less in the labor market (Chiswick and Miller, 2008, 2009; Ferrer and Riddell, 2008; Nanos and Schluter, 2014). The early study of Hong Kong is also consistent with the literature (Lam and Liu, 2002). Hence, although the immigrants to Hong Kong might have a little overall effect on the general wage (Suen, 2000), the coming of immigrants contribute to the increase in income inequality in Hong Kong (Lam and Liu, 1998). While the immigrants affect the labor market in different dimensions, their very presence would imply a further tightening of the housing market, because every human being demands a shelter. An increase in the population imposes additional pressure on the apparent housing shortage. Some social scientists report that there is a deterioration of attitude against Mainland Chinese immigrants in Hong Kong (Lee et al., 2016; Lee and Chou, 2018). Some authors seek to investigate the effect of Mainland Chinese immigrants on the housing price and rent in Hong Kong. We conjecture that the immigrant issue compounds with the Hong Kong identity problem, and exerts pressure on the housing market policies in Hong Kong. We leave the empirical validation to future research.

(Figure 6 about here)

\section{More Time Series Analysis}

The previous section provides an informal overview of the Hong Kong housing market and the macroeconomy. In this section, we attempt to provide more stylized facts with the minimum statistical model. In particular, we show how the time series of the aggregate data in Hong Kong can be decomposed into different components and the implications of such a diagnosis. To our knowledge, this is the first time to apply the unobserved component approach to decompose time series of aggregate data in Hong Kong. In section 3.1, we explain the justifications and the setup of our econometric model. Readers who are not interested in such technical issues can go directly to section 3.2, which presents our decomposition results of the Hong Kong aggregate data.

\subsection{Econometric Model}

We have several considerations. First, for Hong Kong and Mainland China, 
the aggregate data is non-stationary. There are some "upward trend" or "growth components" in the data. Hence, statistical moments are not well defined in the raw data, and we need to appropriately "de-trend" the data. Second, it is well known that the growth of GDP and other aggregate variables are stochastic (Chu et al., 2012; Durlauf and Quah, 1999; King et al., 1988; Leung and Quah, 1996; Leung et al., 2006; Tang et al., 2008). It means that the traditional method of removing a linear trend would not be appropriate. Third, we try to maintain a "reduced form" approach and do not impose much "structure" in the statistical model. A merit of this approach is to establish some stylized facts that would inform the future development of theoretical modeling (Cooley, 1995). Fourth, the model should help us to visualize the differences between changes that happen in the "trend" component (i.e., changes that would have lasting effects) from structural breaks (i.e., dramatic changes that occur once and for all). Fifth, if possible, we would like to take advantage of the relatively new development in time series econometrics, which may help us to uncover overlooked "stylized facts."

Based on these considerations, we consider the following unobserved component model to be appropriate (Commandeur and Koopman, 2007). It allows us to decompose a time series into a trend component, a seasonal component, a cyclical component, an irregular component, and the possible structural breaks. Both the number and timing of structural breaks are endogenous in the sense that if there is no structural break in the data, our econometric model would truthfully report there is no break. On the other hand, if there are multiple structural breaks, the model would also faithfully reflect those breaks. Formally, our econometric model for the aggregate quarterly data is as follows, ${ }^{18}$

$$
y_{t}=\mu_{t}+\gamma_{t}+v_{t}+\sum_{j=1}^{h} \lambda_{j} w_{j, t}+\varepsilon_{t}, \quad \varepsilon_{t} \sim N I D\left(0, \sigma_{\varepsilon}^{2}\right), t=1, \ldots, T
$$

Where $y_{t}$ is the raw time series data, $\mu_{t}$ is the trend component, $\gamma_{t}$ is the seasonal component, $v_{t}$ is the cyclical component, $w_{j, t}$ are the level breaks, and $\varepsilon_{t}$ is the

\footnotetext{
${ }^{18}$ Data for Hong Kong is collected from Census and Statistic Department and Rating and Valuation Department. Data for China is collected from CEIC. Real variables are obtained directly from the official sources, except for real housing prices and rents of Hong Kong and the real GDP of China which is calculated by dividing the nominal variables by CPI. Real GDP per capita of Hong Kong is calculated by dividing Real GDP by population (interpolated from semi-annual data).
} 
irregular component. Following the literature, the trend component-is specified as

$$
\begin{gathered}
\mu_{t}=\mu_{t-1}+\beta_{t-1}+\eta_{t}, \quad \eta_{t} \sim N I D\left(0, \sigma_{\eta}^{2}\right), \\
\beta_{t}=\beta_{t-1}+\zeta_{t}, \quad \zeta_{t} \sim N I D\left(0, \sigma_{\zeta}^{2}\right)
\end{gathered}
$$

where $\beta_{t}$ is the slope or gradient of the trend. $\varepsilon_{t}, \eta_{t}$, and $\zeta_{t}$ are mutually uncorrelated. Thus, our formulation allows for a change in the "growth rate," if any. Some previous research argues that the seasonal component is important and may bias our estimation if we neglect it (Beaulieu and Miron, 1992; Brendstrup et al., 2004). We do not ex-ante conduct seasonal adjustment on the series. Rather, we remove the seasonal component through the unobserved component model. The time-varying seasonal can be established in a time-varying dummy seasonal form (see, among others, Koopman and Oom (2011)):

$$
\gamma_{t+1}=-\gamma_{t}-\cdots-\gamma_{t-s+2}+\omega_{t}, \quad \gamma_{t+j}=\gamma_{t+j-s}, \quad \omega_{t} \sim N I D\left(0, \sigma_{\omega}{ }^{2}\right),
$$

where $s$ is the number of seasonal frequencies in a period (i.e., $s=4$ for quarterly data), and the disturbance series $\omega_{t}$ is serially independent and mutually independent of all other disturbance series, for $t=S-1, \ldots, T$ and $j=2, \ldots, S-1$. The initial variables $\gamma_{\mathrm{S}-1}, \ldots, \gamma_{1}$ are treated as unknown coefficients that need to be estimated together with the other coefficients in the model. If the disturbance variance $\sigma_{\omega}$ is estimated to be zero, this stochastic formulation of seasonal component reduces to a deterministic form.

Our specification of the cyclical component is standard,

$$
\left[\begin{array}{c}
v_{t} \\
v_{t}^{*}
\end{array}\right]=\rho_{v}\left[\begin{array}{cc}
\cos \lambda_{c} & \sin \lambda_{c} \\
-\sin \lambda_{c} & \cos \lambda_{c}
\end{array}\right]\left[\begin{array}{c}
v_{t-1} \\
v_{t-1}^{*}
\end{array}\right]+\left[\begin{array}{c}
\kappa_{t} \\
\kappa_{t}^{*}
\end{array}\right]
$$

where $0<\rho_{v}<1$ is a damping factor, $0 \leq \lambda_{c} \leq \pi$ is the frequency, in radians. $\kappa_{t}$ and $\kappa_{t}^{*}$ are two mutually uncorrelated NID disturbances with zero mean and common variance $\sigma_{\kappa}{ }^{2}$. A merit of this specification is to include both regular and irregular cycles.

The structural break terms $w_{j, t}$, which are also known as “intervention variables," take the following forms:

$$
\begin{gathered}
w_{t}=\left\{\begin{array}{l}
0 \text { for } t \neq \tau \\
1 \text { for } t=\tau
\end{array}\right. \text { for outliers, } \\
w_{t}=\left\{\begin{array}{l}
0 \text { for } t<\tau \\
1 \text { for } t \geq \tau
\end{array}\right. \text { for level breaks }
\end{gathered}
$$


For detecting level breaks and outliers, a t-test for auxiliary residuals would be carried out. Table 1 shows different variations of the unobserved component model. For growth rates, we employ model 1-2 and 5-8 (without a cycle); for level data, we use 3-4 and 9-12 (with a cycle). Our model selection procedures are as follows. (1) We estimate a candidate model without any level breaks. (2) We conduct a t-test for the auxiliary residuals to detect level breaks. (3) We include level breaks detected into the candidate model and repeat (2). To guard against the possibility of "over-fitting,” we, therefore, do not add interventions for every level break detected. (4) We use both AIC and BIC for model selection. Table 2 shows the selected models.

(Table 1 and 2 about here)

Before we present our results of the decomposition, we first justify our adoption of the unobserved component approach. A merit of using the unobserved component approach via Kalman filter is that one can control for outliers and breaks (if any), which may otherwise bias our estimation. To illustrate this, we compare the Kalman filter approach with the Christiano-Fitzgerald (bandpass) filter and the Hodrick-Prescott (HP) filter. The latter two do not control for outliers and breaks. We use the real export of Hong Kong (level data) as an example. First, we follow the usual practice to adjust for the seasonal pattern by using the Census Bureau's X-13 procedure. ${ }^{19}$ Then, we employ different filters to decompose the seasonally adjusted series. Figure 7a shows that the estimated trends of different filters are very similar. Now, we add an artificial level break to the series by multiplying the data by 1.05 starting from 1996Q1. We then use the three filters to decompose the artificial series. If the Kalman filter approach works well in controlling for the break, the trend and non-trend components will look similar before and after adding the fake break. Indeed, Figure 7b shows that it is the case. For the cases of the Christiano-Fitzgerald filter and HP filter, a higher trend results from 1996 onwards since the break is not adequately taken into account. The unobserved component approach via the Kalman

\footnotetext{
${ }^{19}$ Previously, we estimate the seasonal components by formulating $\gamma_{t}$ in our model. However, the usual practice before applying the HP filter and the Christiano-Fitzgerald is to conduct seasonal adjustments on the series since they do not consider seasonal components within their frameworks. Therefore, to be consistent, we drop $\gamma_{t}$ in our model for this comparison part and adjust for the seasonal pattern by using the Census Bureau's X-13 procedure before applying any filters.
} 
filter is more robust when facing breaks and outliers.

(Figure 7 about here)

\subsection{Decomposition of Hong Kong aggregate data}

Now, we present our decomposition results. A few remarks are in order. Constrained by data availability, some variables may have a more extended time series than the others. We focus on real variables (i.e., the inflation factor has been removed). To facilitate the comparison, we present the decomposition of different variables in the same format. The first panel shows the raw data (solid black line) and the trend with structural break components (red dotted line). The second panel shows the seasonal part. The third panel shows the irregular part, which we can interpret as "noises." Notice that the scales of the three panels may vary.

Figure 8a shows the real GDP growth of Hong Kong over the years. It captures the economic downturn due to the stock market crash in 1973 and the subsequent rebound. It also captures the "short recession" in 1985. Interestingly, it shows that the trend of real GDP growth slows down, starting from the first quarter of 1989. After the Joint Anglo-Chinese Declaration in 1983, some people Hong Kong consider the possibility of migration. The 4th June event occurred in Beijing 1989, and the subsequent trade restrictions imposed by the U.S. on China accelerate the migration. ${ }^{20}$ According to Skeldon (1990, p. 502), the average emigration from Hong Kong is around 20,000 people between 1980 and 1986. Starting 1987, the annual emigration from 1987 to 1991 are 30,000, 45,800, 42,000, 62,000, and 58,000 respectively. Furthermore, Skeldon (1990, p.505-6) reports that “... For example, the applications for certificates of no criminal conviction, which are required by most countries in the course of visa applications, averaged around 3,200 a month over the first half of 1989 but jumped to an average of 6,200 a month for the second half of the year (there were 7,225 applications in August 1989 alone). The number of visa petitions to the United States consulate in August 1989 was 85 percent higher than for the same month in the previous year while the number of petitions for September was

\footnotetext{
${ }^{20}$ Due to the lobby of the U.S. business sector, those trade restrictions were removed soon (Dietrich, 1999; Skidmore and Gates, 1997). For more discussion of the $4^{\text {th }}$ June event, see Zhao (2001), among others.
} 
up by 233 percent.” Since emigrants tend to be well-educated, the sudden increase in emigration gives pressure to the supply of human capital, and the Hong Kong government is forced to respond. Wong (1992, p.13) reports that “... Hong Kong government announced in 1989 an accelerated plan to increase the number of first year, first degree places from about 7,000 at that time to 15,000 in 1995. This meant making tertiary places available to 18 per cent of the relevant age group in 1995 as compared to the 7 per cent in 1989. The dramatic move was made after the shock of the Tiananmen incident in China. The main aims, according to the government, were to cope with the exodus of talents, to upgrade skills for the future, and to satisfy parental demands so as to restore public confidence in the territory.”

(Figure 8 about here)

Recent empirical research confirms that human capital is crucial to economic growth (Hanushek et al., 2017; Hanushek and Woessmann, 2015, 2016). Thus, such massive emigration would dampen the economic growth in Hong Kong. Our decomposition confirms such intuition. We identify a structural break in the trend component of the economic growth rate in 1989Q1 (Figure 8a). While the drop may appear to be "small," its importance should not be underestimated. We have done some "back of the envelope" calculation. First, we normalize the real GDP of Hong Kong in 1988Q4 (i.e., the fourth quarter of 1988) to be 100. Before the structural break occurs (before 1989Q1), the trend component of the real GDP grows at 2.17\% per quarter. After the structural break (starting from 1989Q1), the average quarterly growth rate of the trend component becomes 1.03\%. The real GDP in 2019Q2 is 349.1. If the structural break never happened, the real GDP in 2019Q2 would be 1372.32, which is almost four times the observed data.

Since this "political scar" in the trend component of the real GDP growth rate in Hong Kong is new, some "robustness checks" are necessary. The first objection is that China was also hurt by the trade restrictions imposed by the U.S. at that time. We should check whether such a political scar is also found in the Chinese GDP data. Unfortunately, we are unable to access quarterly real GDP data of China with a comparable sampling period. Figure $8 \mathrm{~b}$ displays what we can find so far. Both the raw 
data and the trend component of the real GDP growth of China behave differently from Hong Kong. The second possible objection is that the changing population of Hong Kong over the sampling period, and hence the growth rate of the aggregate GDP may be affected by the growth rate of the people. Unlike many metropolitans in the world, Hong Kong has a fixed boundary, and hence the population factor may be significant. Therefore, we repeat the exercise with per capita real GDP growth and report the results in Figure 8c. The same permanent downward shift is also observed in the first quarter of 1989. Hence, the diminished growth trend is not about the quantity of the population, but rather the quality of the people.

Figure 8d shows the decomposition results of the unemployment rate of Hong Kong. Interestingly, the trend component of the unemployment rate increases around 1989, which is the same year the permanent downward shift in the real GDP growth rate occurs. Notice that the unemployment rate is often a lagging indicator (NBER, 2020), and hence the structural break occurs in 1989Q1 would affect the unemployment rate in subsequent quarters. The unemployment rate experiences a further upward change around the Asian Financial Crisis. It hits a peak around 2003 and then started to decline. It stabilizes at a relatively low level after 2011. Yet the trend component of the unemployment rate never restores the low level in the late 1980s. Again, to facilitate comparison, Figure 8e displays the decomposition results for the counterpart of China. Adjusting for the fact that the sampling period of China is shorter, the China unemployment rate exhibits a very different pattern. It is not surprising since China is a vast country and has a more complicated economic environment.

Since some authors argue that international trade tends to lead the housing market in Hong Kong (Ho and Wong, 2008; Leung et al., 2006), Figure 8f shows the growth rate of the real trade volume, which is the sum of import and export (including re-exports). The trend component displays a downward trend. It means that the trade volume grows at a decreasing rate over the sampling period. Figures $8 \mathrm{~g}$ and $8 \mathrm{~h}$ show the decomposition of the growth rates of export and import, respectively. They are qualitatively the same. These graphs are consistent with the observation that Hong Kong becomes increasingly dependent on the financial sector, and the weight on international trade diminishes over time. 
Some authors debate whether we should model the joint dynamics of nondurable consumption and housing (Davis and Martin, 2009; Kwan et al., 2015; Leung, 2007, 2014; Leung et al., 2011; Piazzesi, 2007). Therefore, we also conduct a decomposition of the aggregate consumption of Hong Kong and present the results in Figure 8i. The trend component is downward sloping, suggesting that the aggregate real consumption of Hong Kong is growing at a decreasing rate. Such a downward trend may go unnoticed because the seasonal fluctuations of consumption are large. One possible interpretation is as follows. In contrast to many theoretical models, housing in practice is not infinitely divisible. Facing continually increasing housing prices, potential, as well as constrained home-buyers, need to reduce non-durable consumption to pay for the home mortgage.

We also decompose the aggregate time-series of investment, as some authors highlight the joint dynamics of residential and commercial investment (Greenwood and Hercowitz, 1991; Iacoviello and Neri, 2010; Jin et al., 2012; Jin and Zeng, 2004). Unfortunately, there is only one aggregate investment time series for Hong Kong, and we are unable to separate residential investment from commercial investment. Figure 8j shows that the trend component of the aggregate real investment in Hong Kong also displays a downward trend. Again, covered by the volatile seasonal cycles, an average citizen might not detect such a downward trend. At the same time, as the aggregate investment is growing at a decreasing rate, and the population is increasing at the same time, the economy may not be able to generate enough "good jobs." Figure 8k shows the decomposition results of the real wage in Hong Kong. While the raw data of the wage growth rate is volatile, the trend component is close to zero. It is consistent with our previous result that, relative to the per capita GDP, the wage index and the household income suffers a deterioration over time.

Fiscal Policies impact the housing market (Alpanda and Zubairy, 2017; Jin and Zeng, 2007). Economists have developed different tools to assess the impact of various fiscal policies, such as generational accounting (Auerbach et al., 1994). Unfortunately, we have no access to the needed data. Therefore, we only decompose the growth rate of real government spending. Figure 81 shows that except for a few "unusual quarters," the trend component of the real government spending is almost a constant. Throughout the sampling period, there are many structural reforms in the government, including the privatization of some shopping malls and parking lots 
located in public rental housing. However, the data we can access is simply an aggregate sum, and we can only leave a more detailed analysis of future research.

Finally, Figures $8 \mathrm{~m}$ and $8 \mathrm{n}$ present the decomposition results of the real house price and rent. Several observations are in order. While the trend components of the real GDP growth, real wage, real trade volume, real consumption, real investment, etc. are like straight lines, the counterparts of the real house price and rent behave very differently. In other words, it may not be easy to predict the "trend" of the house price and rent with merely the trend components of the real variables. Figures $8 \mathrm{~m}$ and 8n also show that, relative to the trend components, the irregular components of both house prices and rent are small. The seasonal factors are significant, but by our construction, they are predictable.

\section{Concluding Remarks}

Why is the housing in Hong Kong so "unaffordable"? We propose a variety of reasons. First, there is a measurement issue. Hong Kong has an unusually large public rental sector, and about one-third of the population is insulated from the market fluctuations. Another one-seventh live in the housing of subsidized ownership. The private housing market accounts for roughly half of the people. The usual house priceto-income ratio may not be an appropriate metric for the housing affordability in Hong Kong. Second, there seem to be some long term reasons, including persistent GDP growth, persistent population growth, extended longevity, etc., which tend to drive up the housing demand.

On the other hand, relative to the GDP per capita, we show that the wage index and the household income are unable to catch up with the house price. The "competitive labor market paradigm" is apparently at odds with the data. Besides, we provide time series decomposition of many time-series data of Hong Kong. We find that since early 1989, the trend component of the real GDP growth suffers a significant drop, which we label as a "political scar." The trend component of the real wage growth is almost zero, and the counterpart of real consumption growth and real investment growth declines steadily. Thus, the unaffordability of Hong Kong housing may reflect the loss of growth momentum in Hong Kong. At the same time, the trend component of both real house prices and rent are volatile and do not seem to be in line with the counterparts of the 
real variables we have decomposed. In Leung et al. (2020) and other ongoing research, we point to the possibility of restricted housing supply. This issue alone may not explain the whole puzzle, and more research efforts are needed in the future. 


\section{Reference}

Abiad, A., Baris, K., Bernabe, J. A., Bertulfo, D. J., Camingue-Romance, S., Feliciano, P. N., Mariasingham, M. J., and Mercer-Blackman, V., 2018, The impact of trade conflict on developing Asia, Asian Development Bank, mimeo.

Alpanda, S., and Zubairy, S., 2017, Addressing household indebtedness: Monetary, fiscal or macroprudential policy?, European Economic Review, 92(C), 47-73.

Amiti, M., Redding, S. J., and Weinstein, D., 2019, The Impact of the 2018 Trade War on U.S. Prices and Welfare, mimeo.

Auerbach, A. J., Gokhale, J., and Kotlikoff, L. J., 1994, Generational Accounting: A Meaningful Way to Evaluate Fiscal Policy, Journal of Economic Perspectives, 8(1), 73-94.

Autor, D., Dorn, D., Katz, L. F., Patterson, C., and Van Reenen, J., 2017, The Fall of the Labor Share and the Rise of Superstar Firms, mimeo.

Bardhan, A., Edelstein, R., and Kroll, C., eds, 2012, Global Housing Markets: Crises, Institutions and Policies, New York: John Wiley \& Sons.

Bardhan, A., Edelstein, R., and Leung, C. K. Y., 2004, A Note on Globalization and Urban Residential Rents, Journal of Urban Economics, 56, 505-513.

Beaulieu, J.K., and Miron, J.A., 1992, Why do countries and industries with large seasonal cycles also have large business cycles? Quarterly Journal of Economics 107, 621-656.

Becker, G., 1994, Human Capital: A Theoretical and Empirical Analysis with Special Reference to Education, Third Edition, National Bureau of Economic Research.

Behrens, K., Kanemoto, Y., and Murata, Y., 2015, The Henry George Theorem in a secondbest world, Journal of Urban Economics, 85(C), 34-51.

Ben-Shafar, D., Leung, C., and Ong, S. E., 2008, Mortgage Market Worldwide, Oxford: Blackwell.

Bertaud, A., 2018, Order without Design: How Markets Shape Cities, Cambridge: MIT Press.

Bredtmann, J., Otten, S., and Rulff, C., 2018, Husband's Unemployment and Wife's Labor Supply: The Added Worker Effect across Europe, ILR Review, 71(5), 1201-1231.

Brendstrup, B., Hylleberg, S., Nielsen, M. R., Skipper, L., and Stentoft, L., 2004, Seasonality In Economic Models, Macroeconomic Dynamics, 8(3), 362-394.

Bryan, M., and Longhi, S., 2018, Couples' Labour Supply Responses to Job Loss: Growth and Recession Compared, Manchester School, 86(3), 333-357.

Case, K., and Quigley, J., 2008, How Housing Booms Unwind: Income Effects, Wealth Effects, and Feedbacks through Financial Markets, European Journal of Housing Policy, 8(2), 161-180.

Chang, K. L., Chen, N. K., and Leung, C. K. Y., 2012, The Dynamics of Housing Returns in Singapore: How Important are the International Transmission Mechanisms?, Regional Science and Urban Economics, 42(3), 516-530. 
Chang, K. L., Chen, N. K., and Leung, C. K. Y., 2013, In the shadow of the United States: The International Transmission Effect of Asset Returns, Pacific Economic Review, 18(1), 1-40.

Chang, K. L., Chen, N. K., and Leung, C. K. Y., 2016, Losing Track of The Asset Markets: The Case of Housing and Stock, International Real Estate Review 19(4), 435-492.

Chen, K., and Wen, Y., 2016, The Great Housing Boom of China, mimeo.

Chen, N. K., and Leung, C. K. Y., 2008, Asset Price Spillover, Collateral and Crises: with an Application to Property Market Policy, Journal of Real Estate Finance and Economics, 37(4), 351-385.

Chen, T., Liu, L. X., Xiong, W., and Zhou, L. A., 2017, Real Estate Boom and Misallocation of Capital in China, mimeo.

Chen, S. W., and Shen, C. H., 2006, When Wall Street conflicts with Main Street-The divergent movements of Taiwan's leading indicators, International Journal of Forecasting, 22, 317- 339 .

Cheung, Y. W., Chow, K. K., and Yiu, M. S., 2017, Effects of capital flow on the equity and housing markets in Hong Kong, Pacific Economic Review, 22(3), 332-349.

Chiswick, B. R., and Miller, P. W., 2008, Why is the payoff to schooling smaller for immigrants?, Labour Economics, 15(6), 1317-1340.

Chiswick, B. R., and Miller, P. W., 2009, The international transferability of immigrants' human capital, Economics of Education Review, 28(2), 162-169.

Chong, T. T. L., and Yiu, A. W. H., 2019, The Nexus between Visitor Arrivals and Residential Property Rents in Hong Kong, Pacific Economic Review, forthcoming.

Chow, Y. F., Wong, N., Leung, C. K. Y., Cheng, E. H. F., and Yan, W. H., 2002, Hong Kong Real Estate Market: Facts and Policies, Hong Kong: Ming Pao Publishing (In Chinese).

Chu, A. C., Leung, C. K.Y., and Tang, E., 2012, Intellectual property rights, technical progress and the volatility of economic growth, Journal of Macroeconomics, 34(3), 749-756.

Commandeur, J.F., and Koopman, S.J., 2007, An Introduction to State Space Time Series Analysis, Oxford: Oxford University Press

Cooley, T., ed., 1995, Frontiers of Business Cycle Research, Princeton: Princeton University Press.

Dao, M., Das, M., Koczan, Z., Lian, W., 2017, Why is Labor Receiving a Smaller Share of Global Income? Theory and Empirical Evidence, mimeo.

Davis, M., and Martin, R. F., 2009, Housing, home production, and the equity- and valuepremium puzzles, Journal of Housing Economics, 18(2), 81-91.

Davis, M., and Van Nieuwerburgh, S., 2014, Housing, Finance and The Macroeconomy, NBER Working paper No. 20287.

Demographia, 2019, 15th Annual Demographia International Housing Affordability Survey: 2019, mimeo. 
Deng, Y., Girardin, E., Joyeux, R., and Shi, S., 2017, Did Bubbles Migrate from The Stock to The Housing Market in China Between 2005 and 2010, Pacific Economic Review 22(3): 276292.

Deng, Y., Sing, T. F., and C. Ren, 2014, The Story of Singapore’s Public Housing: From a Nation of Home-Seekers to a Nation of Homeowners, in J. Chen et al. (eds.), The Future of Public Housing: Ongoing Trends in the East and the West, Berlin: Springer-Verlag, DOI 10.1007/978-3-642-41622-4_7.

Dietrich, J. W., 1999, Interest Groups and Foreign Policy: Clinton and the China MFN Debates, Presidential Studies Quarterly, 29(2), pp. 280-296.

DiPasquale, D., 1999, Why don’t we know more about housing supply? Journal of Real Estate Finance and Economics, 18(1), 9-23.

DiPasquale, D., and Wheaton, W., 1996, Urban Economics and Real Estate Markets. Englewood Cliffs, NJ: Prentice-Hall.

Durlauf, S. N., and Quah, D. T., 1999, The new empirics of economic growth, in Taylor, J. B.., and Woodford, M., ed., Handbook of Macroeconomics, volume 1, 235-308.

Erosa, A., Luisa Fuster, L., Kambourov, G., and R. Rogerson, 2017, Hours, Occupations, and Gender Differences in Labor Market Outcomes, NBER Working Papers 23636.

Favilukis, J., Ludvigson, S., and Van Nieuwerburgh, S., 2017, The Macroeconomic Effects of Housing Wealth, Housing Finance and Limited Risk Sharing in General Equilibrium, Journal of Political Economy 125(1), 140-222.

Ferrer, A., and Riddell, W. C., 2008, Education, credentials, and immigrant earnings, Canadian Journal of Economics, 41(1), 186-216.

Funke, M., and Paetz, M., 2018, Dynamic Stochastic General equilibrium-based Assessment of Nonlinear Macroprudential Policies: Evidence from Hong Kong, Pacific Economic Review, 23(4), 632-657.

Garriga, C., Hedlund, A., Tang, Y., and Wang, P., 2017, Rural-Urban Migration, Structural Transformation, and Housing Markets in China, NBER Working paper No. 23819.

George, H., 1879, Progress and Poverty, available from

http://www.henrygeorge.org/pcontents.htm

Glaeser, E., and Gyourko, J., 2018, The Economic Implications of Housing Supply, Journal of Economic Perspectives, 32(1), 3-30.

Gong, Y., and Leung, C. K. Y., 2019, When education policy and housing policy interact: can they correct for the externalities?, mimeo.

Green, R., and Malpezzi, S., 2003, A Primer on U.S. Housing markets and Housing Policy, Washington, D.C.: Urban Institute Press.

Green, R., Malpezzi, S., and Mayo, S., 2005, Metropolitan-Specific Estimates of The Price Elasticity of Supply of Housing, and Their Sources. American Economic Review, 95(2), 334339.

Greenwood, J., and Hercowitz, Z., 1991, The Allocation of Capital and Time over the Business Cycle, Journal of Political Economy, 99(6), 1188-1214. 
Greenwood, J., Guner, N., and Vandenbroucke, G., 2017, Family Economics Writ Large, Journal of Economic Literature, 55(4), 1346-1434.

Gutierrez, G., 2017, Investigating Global Labor and Profit Shares, mimeo.

Guo, M., Lu, L., Sheng, L., and Yu, M., 2018, The Day After Tomorrow: Evaluating the Burden of Trump's Trade War, Asian Economic Papers, 17(1), 101-120.

Hanushek, E., Rivkin, S., and L.L. Taylor, L., 1996, Aggregation and the estimated effects of school resources, Review of Economics and Statistics, 78(4), 611-627.

Hanushek, E., Ruhose, J., and Woessmann, L., 2017, Knowledge capital and aggregate income differences: Development accounting for US states, American Economic Journal: Macroeconomics, 9(4), 184-224.

Hanushek, E., and Woessmann, L., 2015, The Knowledge Capital of Nations: Education and The Economics of Growth, Cambridge, MA: MIT Press.

Hanushek, E., and Woessmann, L., 2016, Knowledge capital, growth, and the East Asian miracle, Science, 351(6271), 344-345.

Hårsman, B., and Quigley, J., 1991, Housing Markets and Housing Institutions: An International Comparison, Berlin: Kluwer Academic Publishers.

Herkenhoff, K., Ohanian, L., and Prescott, E., 2017, Tarnishing The Golden and Empire States: Land-Use Restrictions and The U.S. Economic Slowdown, NBER working paper 23790 .

Ho, L. S., and Wong, G., 2008, Nexus Between Housing And The Macro Economy: The Hong Kong Case, Pacific Economic Review, 13(2), 223-239.

Huang, D., Leung, C. K. Y., and Qu, B., 2015, Do Bank Loans and Local Amenities Explain Chinese Urban House Prices? China Economic Review, 34(C), 19-38.

Huang, D., Leung, C. K. Y., and Tse, C. Y., 2018, What account for the differences in rentprice ratio and turnover rate? A search-and-matching approach, Journal of Real Estate Finance and Economics, 57(3), 431-475.

Hubbard, R. G., and O’Brien, A. P., 2016, Economics. New York: Pearson ( $6^{\text {th }}$ Edition).

Iacoviello, M., and Neri, S., 2010, Housing Market Spillovers: Evidence from an Estimated DSGE Model, American Economic Journal: Macroeconomics, 2(2), 125-164.

Jin, Y., Leung, C. K. Y., and Zeng, Z., 2012, Real Estate, The External Finance Premium and Business Investment: A Quantitative Dynamic General Equilibrium Analysis, Real Estate Economics 40(1), 167-195.

Jin, Y., and Zeng, Z., 2004, Residential investment and house prices in a multi-sector monetary business cycle model, Journal of Housing Economics, 13(4), 268-286.

Jin, Y., and Zeng, Z., 2007, Real estate and optimal public policy in a credit-constrained economy, Journal of Housing Economics, 16(2), 143-166.

Kan, K., Kwong, S. K. S., and Leung, C., 2004, The Dynamics and Volatility of Commercial and Residential Property Prices: Theory and Evidence, Journal of Regional Science, 44(1), 95-123. 
Kaplan, S. N., and Rauh, J., 2010, Wall Street and Main Street: What Contributes to the Rise in the Highest Incomes?, Review of Financial Studies, 23(3), 1004-1050.

Karabarbounis, L., and Neiman, B., 2013, The Global Decline of the Labor Share, Quarterly Journal of Economics, 129(1), 61-103.

Kawano, M., 2014, Optimal process of urbanization in a developing country dynamic Henry George theorem, Letters of Spatial Resource Sciences, 7, 195-204.

King, R. G., Plosser, C. I., and Rebelo, S. T., 1988, Production, growth and business cycles : I. The basic neoclassical model, Journal of Monetary Economics, 21(2-3), 195-232.

Kiyotaki, N., and Moore, J., 1997, Credit Cycles, Journal of Political Economy 105(2), 211248.

Koenig, E. F., Leeson, R., and Kahn, G. A. ed., 2012, The Taylor Rule and the Transformation of Monetary Policy, Stanford: Hoover Institution Press.

Koopman, S. J., and Ooms, M., 2011, Forecasting economic time series using unobserved components time series models, in M.P. Clements and D.F. Hendry (eds.), Oxford Handbook of Economic Forecasting, Oxford: Oxford University Press, Chapter 5, pp. 129-162.

Kwan, Y. K., Leung, C. K. Y., and Dong, J., 2015, Comparing consumption-based asset pricing models: the case of an Asian city, Journal of Housing Economics, 28(C), 18-41.

Lam, K. C., and Liu, P. W., 1998, Immigration, population heterogeneity, and earnings inequality in Hong Kong, Contemporary Economic Policy, 16, 265-276.

Lam, K. C., and Liu, P. W., 2002, Relative returns to skills and assimilation of immigrants in Hong Kong, Pacific Economic Review, 7(2), 229-243.

Lee, S. Y., Ng, I. F. S., and Chou, K. L., 2016, Exclusionary attitudes toward the allocation of welfare benefits to Chinese immigrants in Hong Kong, Asian and Pacific Migration Journal, 25(1), 41-61.

Lee, S. Y., and Chou, K. L., 2018, Explaining attitudes toward immigrants from Mainland China in Hong Kong, Asian and Pacific Migration Journal, 27(3), 273-298.

Leung, C. K. Y., 1999, Income Tax, Property Tax, and Tariff in A Small Open Economy. Review of International Economics, 7(3), 541-554.

Leung, C. K. Y., 2001, Relating International Trade to The Housing Market. Review of Development Economics, 5(2), 328-35.

Leung, C. K. Y., 2003, Economic growth and increasing house price, Pacific Economic Review, 8(2), 183-190.

Leung, C. K. Y., 2004, Macroeconomics and Housing: a review of the literature, Journal of Housing Economics, 13(4), 249-267.

Leung, C. K. Y., 2007, Equilibrium Correlations of Asset Price and Return, Journal of Real Estate Finance and Economics, 34(2), 233-256.

Leung, C. K. Y., 2014, Error correction dynamics of house prices: An equilibrium benchmark, Journal of Housing Economics, 25(C), 75-95. 
Leung, C. K. Y., 2017, Special issue on housing and financial stability: an introduction, Pacific Economic Review, 22(3), 273-275.

Leung, C. K. Y., and Chen, N. K., 2006, Intrinsic cycles of land price: a simple model, Journal of Real Estate Research, 28(3), 293-320.

Leung, C. K. Y., and Chen, N. K., 2017, A special issue on housing, credit markets, and the marcoeconomy: an introduction, Taiwan Economic Review, 45(1), 1-3.

Leung, C. K. Y., Cheung, P. K. Y., and Tang, E. C. H., 2013, Financial Crisis and the Comovements of Housing Sub-markets: Do relationships change after a crisis? International Real Estate Review, 16(1), 68-118.

Leung, C. K. Y., Chow, K. K., Yiu, M. S., and Tam, D. C., 2011, House Market in Chinese Cities: Dynamic Modeling, In-Sampling Fitting and Out-of-Sample Forecasting, International Real Estate Review, 14(1), 85-117.

Leung, C. K. Y., Leong, Y. C. F., and Wong, K. S. K., 2006, Housing price dispersion: an empirical investigation, Journal of Real Estate Finance and Economics, 32(3), 357-385.

Leung, C. K. Y., Leung, T. T. C., and Tsang, B. K. P., 2015, Tax-driven Bunching of Housing Market Transactions: The case of Hong Kong, International Real Estate Review, 18(4), 473501.

Leung, C. K. Y., Ma, W. Y., and Zhang, J., 2014, The Market Valuation of Interior Design and Developers strategies: a simple Theory and some Evidence, International Real Estate Review, 17(1), 63-107.

Leung, C. K. Y., and Ng, J. C. Y., 2019, Macroeconomic Aspects of Housing, in Jonathan H. Hamilton, J. H., Dixit, A., Edwards, S., and Judd, K., ed., Oxford Research Encyclopedia of Economics and Finance, Oxford University Press. doi:

http://dx.doi.org/10.1093/acrefore/9780190625979.013.294

Leung, C. K. Y., Ng, J. C. Y. and Tang, E. C. H., 20, What do we know about Housing Supply? The case of Hong Kong, Economic and Political Studies, 8(1), 6-20.

Leung, C. K. Y., and Quah, D. T., 1996, Convergence, endogenous growth, and productivity disturbances, Journal of Monetary Economics, 38(3), 535-547.

Leung, C. K. Y., Sarpca, S., and Yilmaz, K., 2012, Public Housing Units vs. Housing Vouchers: Accessibility, Local Public Goods, and Welfare, Journal of Housing Economics, 21(4), 310-321.

Leung, C. K. Y., and So, R. W. M., 2004, Hong Kong Asset Market, Hong Kong: Ming Pao Publishing (In Chinese).

Leung, C. K. Y., and Sung, Y. W. ed., 2006, Economic Issues of Hong Kong and the Chinese Mainland: Challenges and Opportunities, Hong Kong: Ming Pao Publishing (In Chinese).

Leung, C. K. Y., and Tang, E. C. H., 2012, Comparing two financial crises: the case of Hong Kong Real Estate Markets, in Bardhan, A., Edelstein, R., and Kroll, C., ed., Global Housing Markets: Crises, Institutions and Policies, eds. by New York: John Wiley \& Sons, 377-398. 
Leung, C. K. Y., and Tang, E. C. H., 2015a, Speculating China economic growth through Hong Kong? Evidence from the stock market IPO and real estate markets, International Real Estate Review, 18(1), 45-87.

Leung, C. K. Y., and Tang, E. C. H., 2015b, Availability, affordability and volatility: the case of Hong Kong housing market, International Real Estate Review, 18(3), 383-428.

Leung, C. K. Y., Tang, S., and Groenewold, N., 2006, Growth Volatility and Technical Progress: A Simple Rent-seeking Model, Journal of Economics, 88(2), 159-178.

Leung, C. K. Y., and Teo, W. L., 2011, Should the optimal portfolio be region-specific? A multi-region model with monetary policy and asset price co-movements, Regional Science and Urban Economics, 41(3), 293-304.

Leung, C. K. Y., and Tse, C. Y., 2017, Flipping in the housing market, Journal of Economic Dynamics and Control, 76(C), 232-263.

Leung, C. K. Y., and Wang, W., 2007, Chinese Housing Market through the lens of DiPasqualeWheaton model: a graphical attempt, International Real Estate Review, 10(2), 131-165.

Leung, C. K. Y., and Wong, K. S., 2004, The construction and related industries in a changing socio-economic environment: the case of Hong Kong, International Real Estate Review, 7(1), 139-176.

Lin, C. C., Mai, C. C., and Wang, P., 2004, Urban Land Policy and Housing in An Endogenously Growing Monocentric City. Regional Science and Urban Economics, 34(3), 241-261.

Lubik, T., 2012, Aggregate labour market dynamics in Hong Kong, Pacific Economic Review, 17(2), 257-279.

Malpezzi, S., 2017, Residential real estate in the U.S. financial crisis, the Great Recession, and their aftermath, Taiwan Economic Review, 45(1), 5-56.

Mandelman, F. and Waddle, A., 2019, Intellectual Property, Tariffs, and International Trade Dynamics, mimeo.

McKinsey, 2017, Housing affordability: A supply-side tool kit for cities, mimeo.

Mera, K., and Renaud, B., eds., 2000, Asia's Financial Crisis and the Role of Real Estate, New York: M. E. Sharpe.

Nanos, P., and Schluter, C., 2014, The composition of wage differentials between migrants and natives, European Economic Review, 65(C), 23-44.

NBER, 2020, The NBER's Business Cycle Dating Procedure: Frequently Asked Questions, available at https://www.nber.org/cycles/recessions_faq.html

Newton, B., 1971, The Impact of Henry George on British Economists, I: The First Phase of Response, 1879-82; Leslie, Wicksteed and Hobson, American Journal of Economics and Sociology, 30(2), 179-186.

OECD, 2016, Be flexible! Background brief on how workplace flexibility can help European employees to balance work and family, mimeo.

Oxfam, 2018, Hong Kong Inequality Report, mimeo. 
Piazzesi, M., and Schneider, M., 2016, Housing and Macroeconomics, NBER Working paper No. 22354.

Piazzesi, M., Schneider, M., and Tuzel, S., 2007, Housing, consumption and asset pricing, Journal of Financial Economics, 83(3), 531-569.

Renaud, B., Kim, K. H., and Cho, M., 2016, Dynamics of Housing in East Asia, New York: John Wiley \& Sons, Ltd.

Saiz, A., 2010, The Geographic Determinants of Housing Supply. Quarterly Journal of Economics, 125(3), 1253-1296.

Skeldon, R., 1990, Emigration and the Future of Hong Kong, Pacific Affairs, 63(4), 500-523.

Skidmore, D., and Gates, W., 1997, After Tiananmen: The Struggle over U.S. Policy toward China in the Bush Administration, Presidential Studies Quarterly, 27(3), 514-539.

Smart, A., 2006, The Shek Kip Mei Myth: Squatters, Fires and Colonial Rule in Hong Kong, 1950-1963, Hong Kong: Hong Kong University Press.

Somerville, C. T., 1999, The Industrial Organization of Housing Supply: Market Activity, Land Supply and the Size of Homebuilder Firms. Real Estate Economics, 27(4), 669-694.

Stigler, G., 1974, Henry Calvert Simons, Journal of Law \& Economics, 17(1), 1-5.

Suen, W., 2000, Estimating the Effects of Immigration in One City, Journal of Population Economics, 13(1), 99-112.

Sung, Y. W., Ng, A. C. Y., Wu, Y., and Yiu, A. W. H., 2015, The Economic Benefits of Mainland Tourists for Hong Kong: The Individual Visit Scheme (IVS) and Multiple Entry Individual Visit Endorsements (M-Permit), mimeo.

Tang, E. C. H., 2017, Real Estate Cycles and Housing Policies in Hong Kong, in Business Cycles: External / Internal Causes, Economic Implications and Consumer Misconceptions, edited by K. Mitchell, Nova Science Publishers, 21-46.

Tang, E. C. H., 2019, Speculate a lot, mimeo.

Tang, S. H. K., Groenewold, N. and Leung, C. K. Y., 2008, The link between institutions, technical change and macroeconomic volatility, Journal of Macroeconomics, 30(4), 1520-1549.

Tham, S. Y., Kam, A. J. Y. and Tee, B. A., 2019, US-China Trade War: Potential Trade and Investment Spill-overs into Malaysia, mimeo.

Tirole, J., 1988, The Theory of Industrial Organization. Cambridge: MIT Press.

Tsai, I.C., 2013, The asymmetric impacts of monetary policy on housing prices: a viewpoint of housing price rigidity, Economic Modelling, 31(C), 405-413.

Tse, C. Y., and Leung, C., 2002, Increasing Wealth and Increasing Instability: The Role of Collateral, Review of International Economics 10(1), 45-52.

Wang, K., and Zhou, Y., 2006, Equilibrium Real Options Exercise Strategies with Multiple Players: The Case of Real Estate Market, Real Estate Economics, 34(1), 1-49. 
Wong, R.Y.C., 1998, On Privatizing Public Housing. Hong Kong: City University of Hong Kong Press.

Wong, S. K., Chau, K. W., Karato, K. and Shimizu, C., 2018, Separating the Age Effect from a Repeat Sales Index: Land and Structure Decomposition, Journal of Real Estate Finance and Economics, 57, 351-366.

Wong, S. L., 1992, Emigration and stability in Hong Kong, Social Sciences Research Centre, Occasional Paper 7, University of Hong Kong.

Wu, J., Gyourko, J. and Deng, Y., 2012, Evaluating Conditions in Major Chinese Housing Markets, Regional Science and Urban Economics, 42(3) 531-543.

Wu, J., Gyourko, J. and Deng, Y., 2016, Evaluating The Risk of Chinese Housing Markets: What We Know and What We Need to Know, China Economic Review, 39(C), 91-114.

Wu, T., Cheng, M. and Wong, K., 2017, Bayesian analysis of Hong Kong's housing price dynamics, Pacific Economic Review, 22, 312-331.

Yeung, Y. M. and Wong, T. K. Y., 2003, Fifty Years of Public Housing in Hong Kong: A Golden Jubilee Review and Appraisal, Hong Kong: Chinese University Press and Hong Kong Housing Authority.

Zhao, D., 2001, The Power of Tiananmen: State-Society Relations and the 1989 Beijing Student Movement. Chicago: University of Chicago Press. 
Reference in Chinese (中文參考讀物)

香港移民潮, 维基百科,

https://zh.wikipedia.org/wiki/\%E9\%A6\%99\%E6\%B8\%AF\%E7\%A7\%BB\%E6\%B0\%91\%E6 $\underline{\text { BD } \% \mathrm{AE}}$

BBC, 2014, 民調：五分之一香港居民考慮移民海外, 2014 年 9 月 22 日

https://www.bbc.com/zhongwen/trad/china/2014/09/140922_hk_survey_migration

股榮, 2019, 一年逾 2 萬內地 [專才] 批來港, 香港新生代的絕望, 蘋果日報(即時財經),

https://hk.finance.appledaily.com/finance/realtime/article/20191204/

鄒崇銘 主編, 2013, 不是土地供應: 香港土地問題的迷思與真象, 印象文字 InPress. ISBN : 978-988-12005-0-1.

㱀崇銘, 2019, 港鐵前路, 何去何從, 信報 Hong Kong Economic Journal, 20191022.

葉潔明, 2019, 政府沒統計移民, 領事館去年數字顯示, 港人定居加拿大台灣創 13 年新高, 眾新聞 CitizenNews, 20190716. 
$\underline{\text { Figures and Tables }}$

$\underline{\text { Table 1. Model specifications }}$

\begin{tabular}{|c|c|c|c|c|}
\hline \multicolumn{5}{|c|}{ Without a slope $\left(\beta_{t}\right)$} \\
\hline Model & $\sigma_{\varepsilon}$ & $\sigma_{\eta}$ & Cycle & \\
\hline 1 & $*$ & 0 & No & \\
\hline 2 & $*$ & * & No & \\
\hline 3 & $*$ & 0 & Yes & \\
\hline 4 & $*$ & * & Yes & \\
\hline \multicolumn{5}{|c|}{ With a slope $\left(\beta_{t}\right)$} \\
\hline Model & $\sigma_{\varepsilon}$ & $\overline{\sigma_{\eta}}$ & $\sigma_{\zeta}$ & Cycle \\
\hline 5 & $*$ & 0 & 0 & No \\
\hline 6 & $*$ & * & 0 & No \\
\hline 7 & $*$ & * & * & No \\
\hline 8 & $*$ & 0 & * & No \\
\hline 9 & $*$ & 0 & 0 & Yes \\
\hline 10 & $*$ & * & 0 & Yes \\
\hline 11 & $*$ & * & * & Yes \\
\hline 12 & $*$ & 0 & * & Yes \\
\hline
\end{tabular}

* indicates any positive values. 
Table 2. Selected models

\begin{tabular}{|c|c|c|c|c|c|c|}
\hline Economy & Variables & Sample period & Model & Seasonal component & R-squared & Breaks and outliers \\
\hline \multirow[t]{12}{*}{ Hong Kong } & Real GDP growth rate & 1973Q2-2019Q2 & 1 & Stochastic & 0.85 & $\begin{array}{l}\text { 1974Q4 O: (+ve); 1976Q1 O: (-ve); } \\
\text { 1985Q2 O: (-ve); } 1989 \text { Q1 L: (-ve); }\end{array}$ \\
\hline & Real GDP per capita growth rate & 1973Q2-2019Q2 & 1 & Stochastic & 0.86 & $\begin{array}{l}\text { 1974Q4 O: (-ve); 1976Q1 O: (+ve); } \\
\text { 1978Q3 O: (-ve); 1985Q2 O: (-ve); } \\
\text { 1989Q1 L: (-ve) }\end{array}$ \\
\hline & Unemployment rate & 1981Q4-2019Q2 & 11 & Stochastic & 0.96 & $\begin{array}{l}\text { 1983Q1 O: (+ve); 1985Q1 L: (-ve); } \\
\text { 2003Q2 L: (+ve); 2009Q1 L: (+ve) }\end{array}$ \\
\hline & Real trade volume growth rate & 1973Q2-2019Q2 & 5 & Stochastic & 0.82 & $\begin{array}{l}\text { 1974Q3 O: (-ve); 1974Q4 O: (-ve); } \\
\text { 1976Q1 O: (+ve); 2009Q1 O: (-ve); } \\
\text { 2009Q2 O: (+ve) }\end{array}$ \\
\hline & Real export growth rate & 1973Q2-2019Q2 & 5 & Stochastic & 0.85 & $\begin{array}{l}\text { 1974Q3 O: (-ve); 1974Q4 O: (-ve); } \\
\text { 1975Q1 O: (+ve); 1976Q1 O: (+ve); } \\
\text { 2009Q1 O: (-ve); }\end{array}$ \\
\hline & Real import growth rate & 1973Q2-2019Q2 & 5 & Stochastic & 0.81 & $\begin{array}{l}\text { 1974Q1 O:(-ve); 1974Q3 O:(-ve); } \\
\text { 1974Q4 O:(-ve); 1975Q3 O:(+ve); } \\
\text { 1998Q3 O:(-ve); 2009Q1 O:(-ve); } \\
\text { 2009Q1 O:(+ve); }\end{array}$ \\
\hline & Real consumption expenditure growth rate & 1973Q2-2019Q2 & 5 & Stochastic & 0.80 & $\begin{array}{l}\text { 1974Q1 O: (-ve); 1974Q4 O: (-ve); } \\
\text { 1976Q3 O: (-ve); 1976Q4 O: (+ve); } \\
\text { 2003Q3 L: (+ve) }\end{array}$ \\
\hline & Real investment growth rate & 1973Q2-2019Q2 & 5 & Stochastic & 0.46 & 1998Q3 O: (-ve) \\
\hline & Real government spending growth rate & 1973Q2-2019Q2 & 5 & Stochastic & 0.87 & $\begin{array}{l}\text { 1981Q1 O: +(ve); 1981Q2 O: -(ve); } \\
\text { 1974Q3 O: +(ve); 1979Q1 O: +(ve); } \\
\text { 1981Q4 O: +(ve); 1992Q1 O: +(ve); } \\
\text { 1997Q3 O: -(ve) }\end{array}$ \\
\hline & Real wage growth rate & 2004Q2-2019Q2 & 5 & Stochastic & 0.82 & 2014Q3 O: (-ve) \\
\hline & Real housing prices growth rate & 1980Q1-2019Q2 & 2 & Stochastic & 0.33 & 1994Q1 O: (+ve); 1998Q4 L: (+ve) \\
\hline & Real housing rents growth rate & 1980Q4-2019Q2 & 2 & Stochastic & 0.65 & $\begin{array}{l}\text { 1989Q3 O: (-ve); 1994Q2 O: (+ve); } \\
\text { 1998Q1 O: (-ve); 1998Q3 O: (-ve); } \\
\text { 2008Q4 O: (-ve); 2009Q1 O: (-ve) }\end{array}$ \\
\hline
\end{tabular}


1999Q4-2019Q2 $12 \quad$ Deterministic $\quad 0.98 \quad$ 2008Q4 L: (+ve); 2009Q1 L: (+ve) respectively. 
Figure 1a: Real Housing Price (RHP) and Real Stock Price (RSP) in Hong Kong (1979 2018)

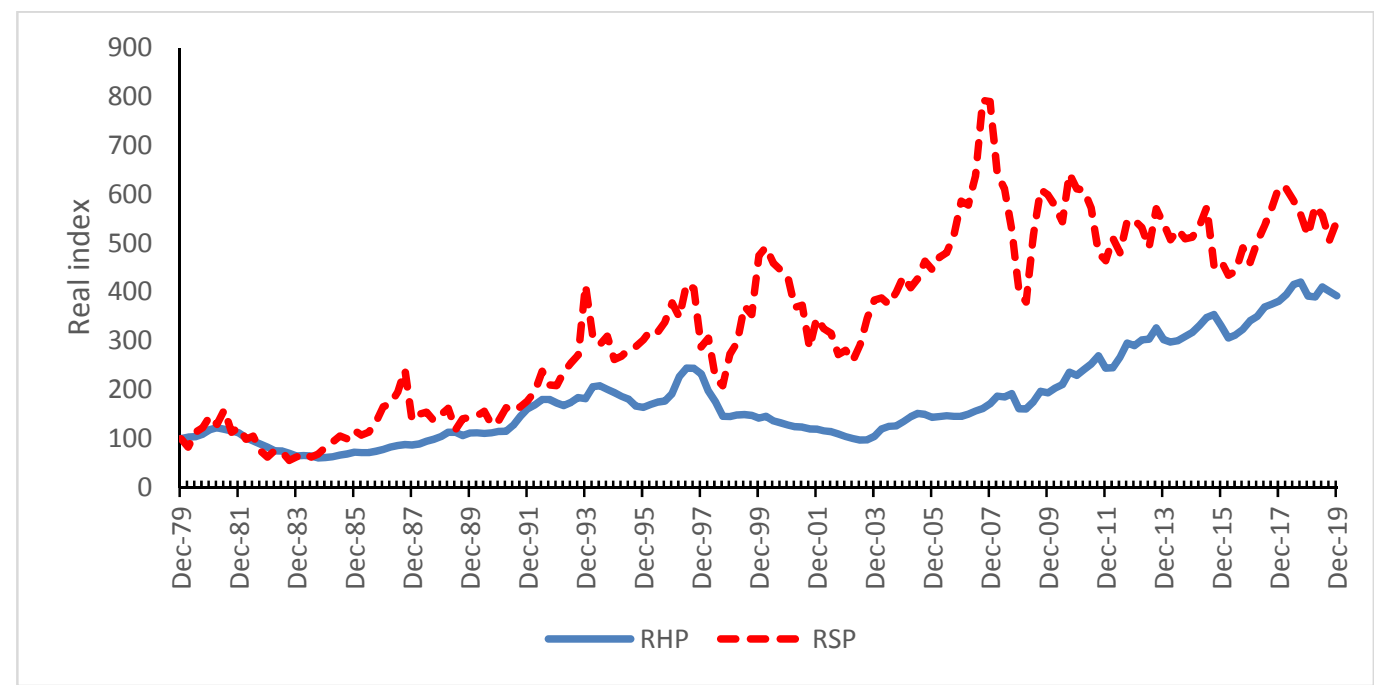

Figure 1b: U.S. Federal Fund rate and Hong Kong Real Housing Price growth rate (1982 2018)

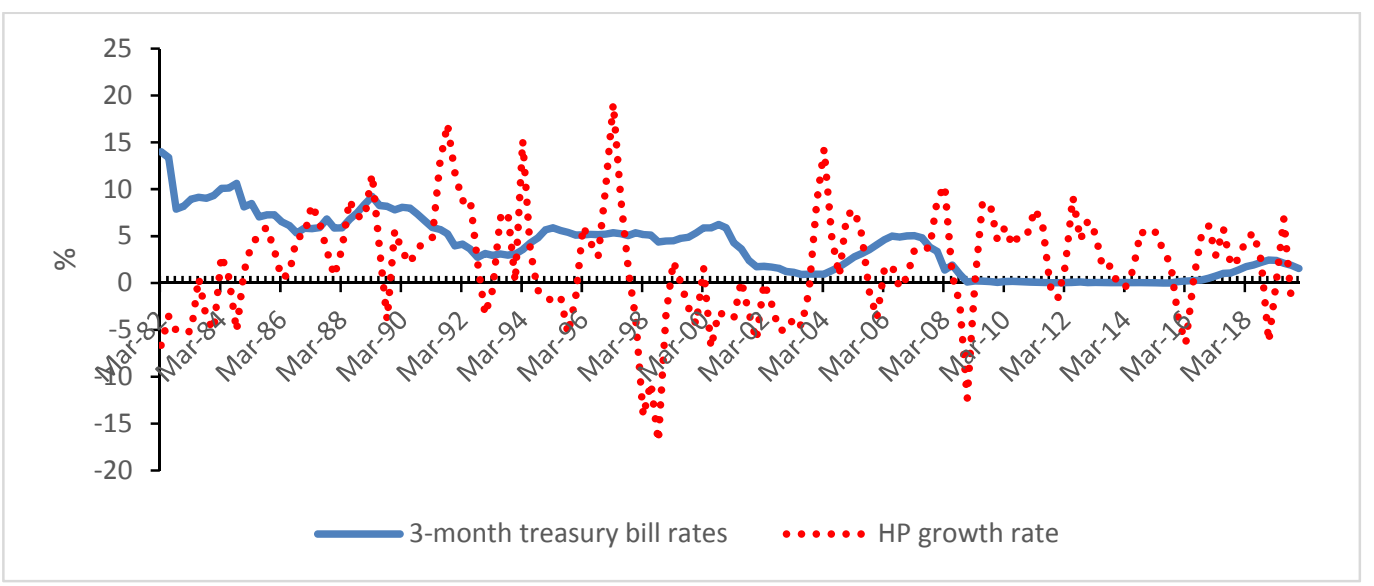


Figure 1c: House price-to-wage ratio in Hong Kong and U.S. (1982 2018)

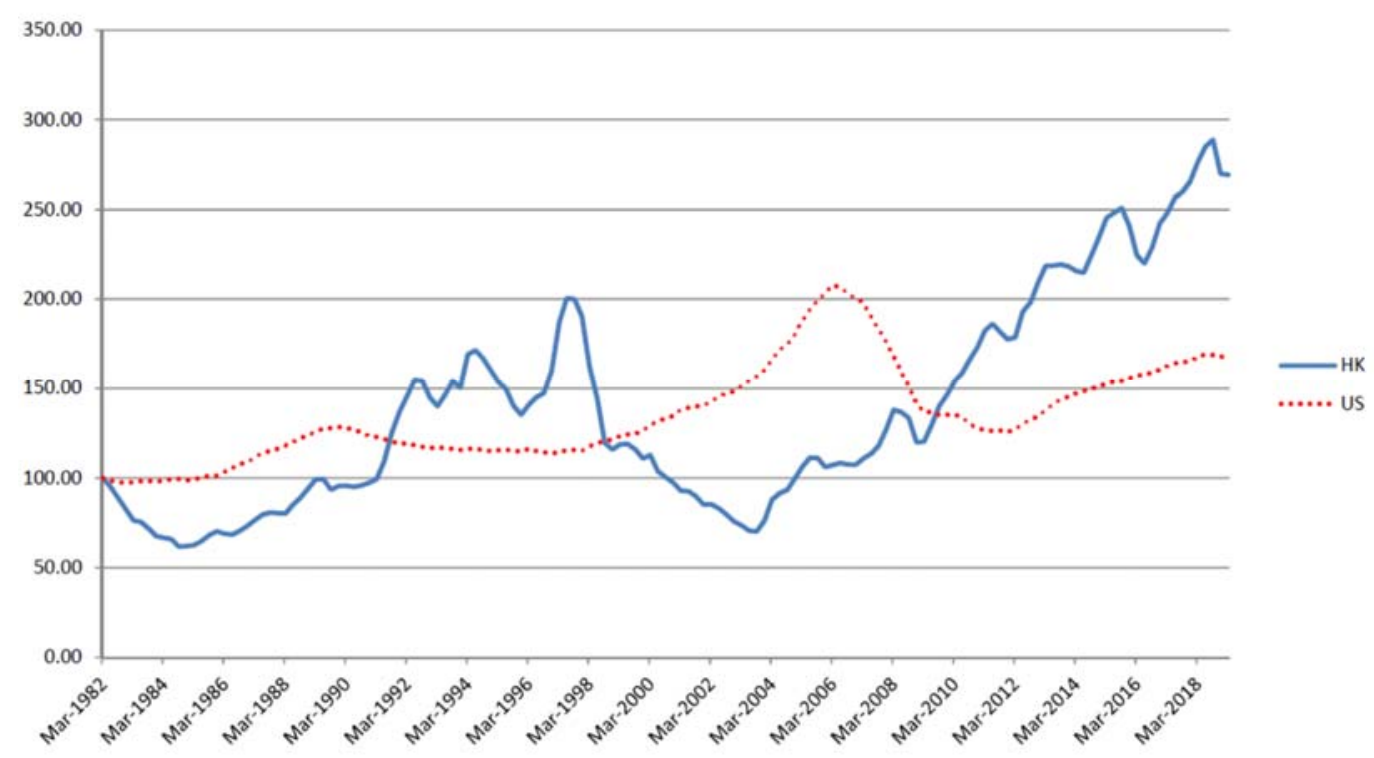


Figure 2a: Distribution of household by types of housing (in thousand)

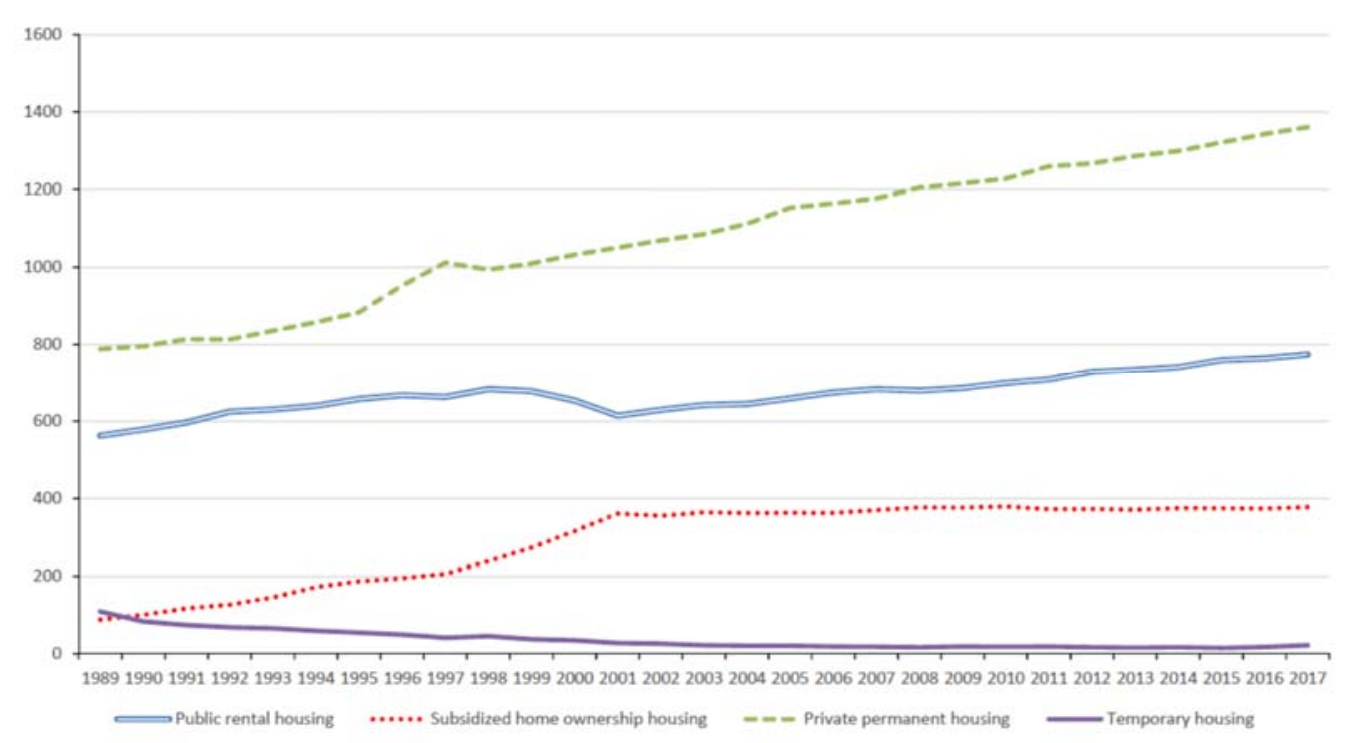

Figure 2b: Distribution of housing stock by type (in thousand)

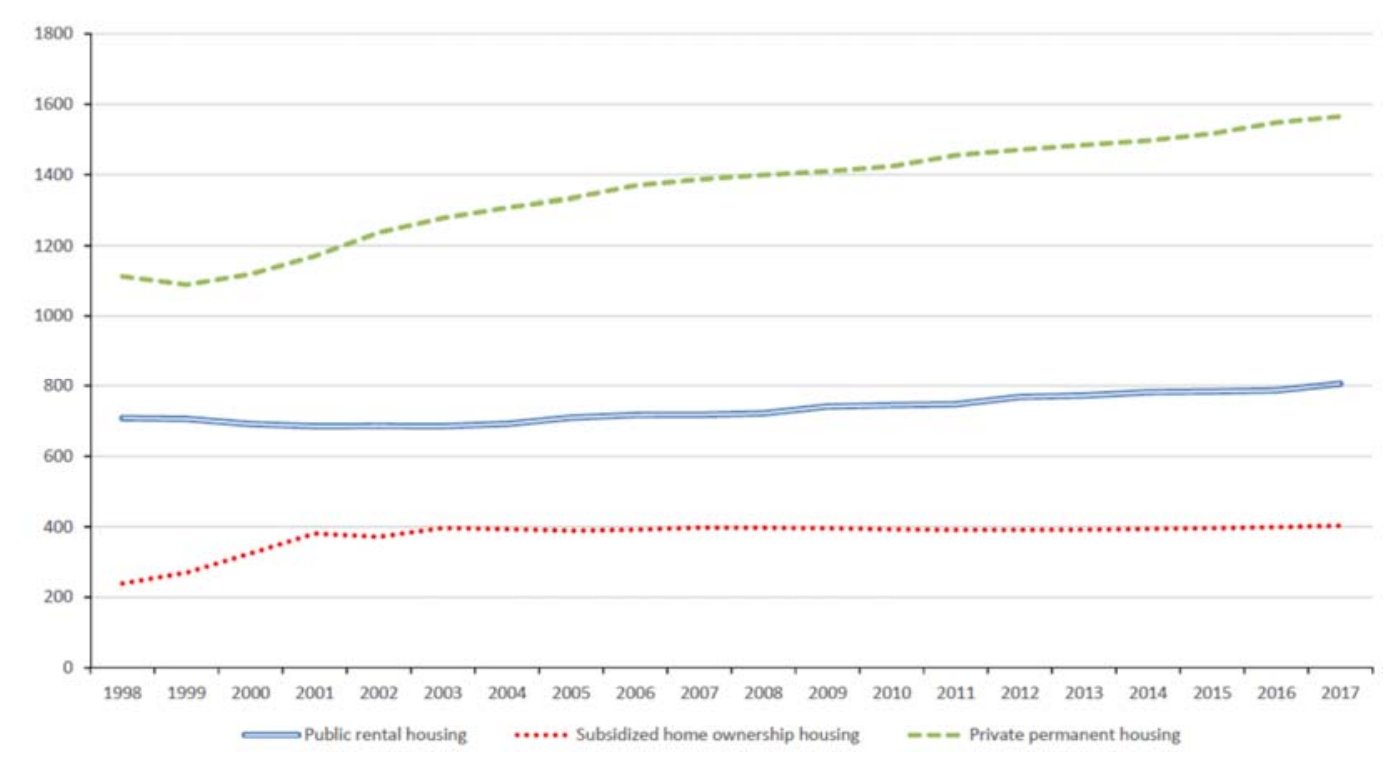


Figure 2c: The rent in public housing is below the private sector counterpart in Hong Kong (1993 2019)

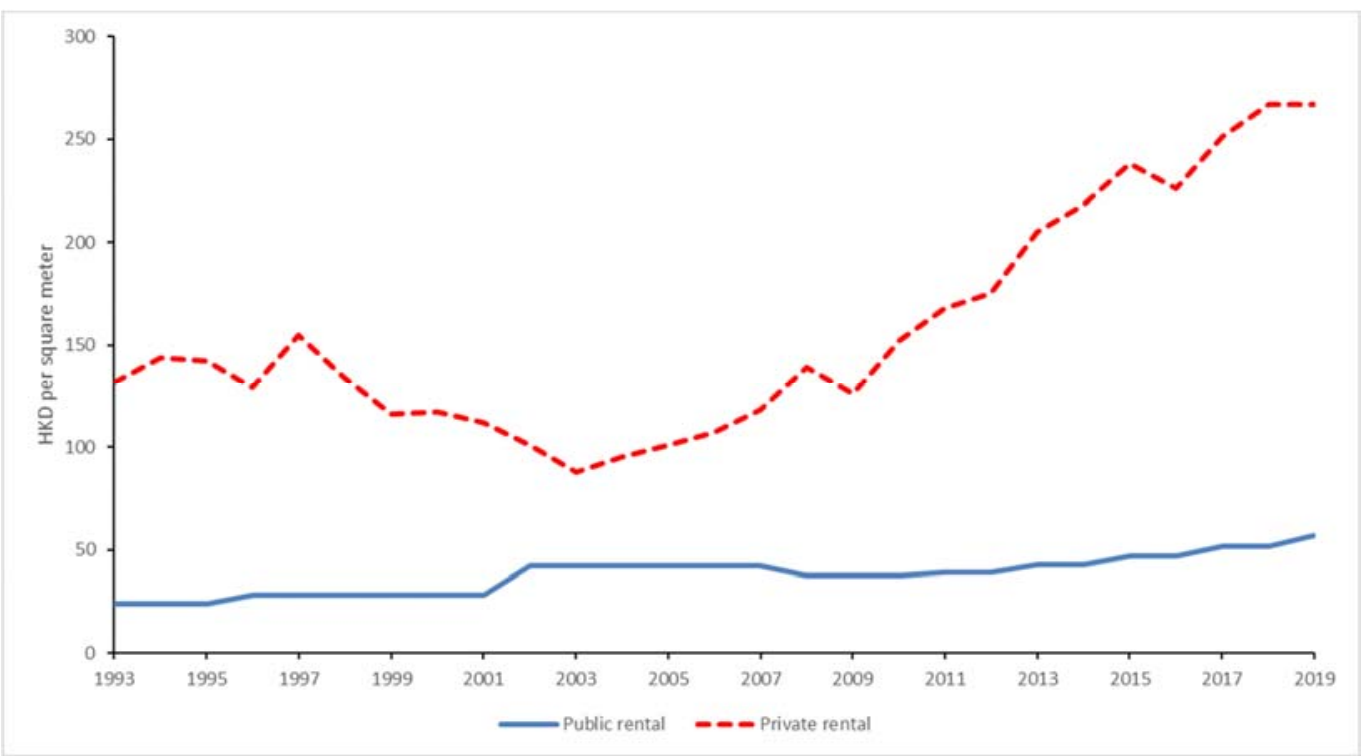

Key: To make the two rental indices comparable, we use the New Territories rental indices. For the public housing rent, we use the one with size 43.3 square meters. For the private housing rent, we use the class $B$ rental index. 
Figure 3a: Hong Kong per capita GDP (real terms) increases over time

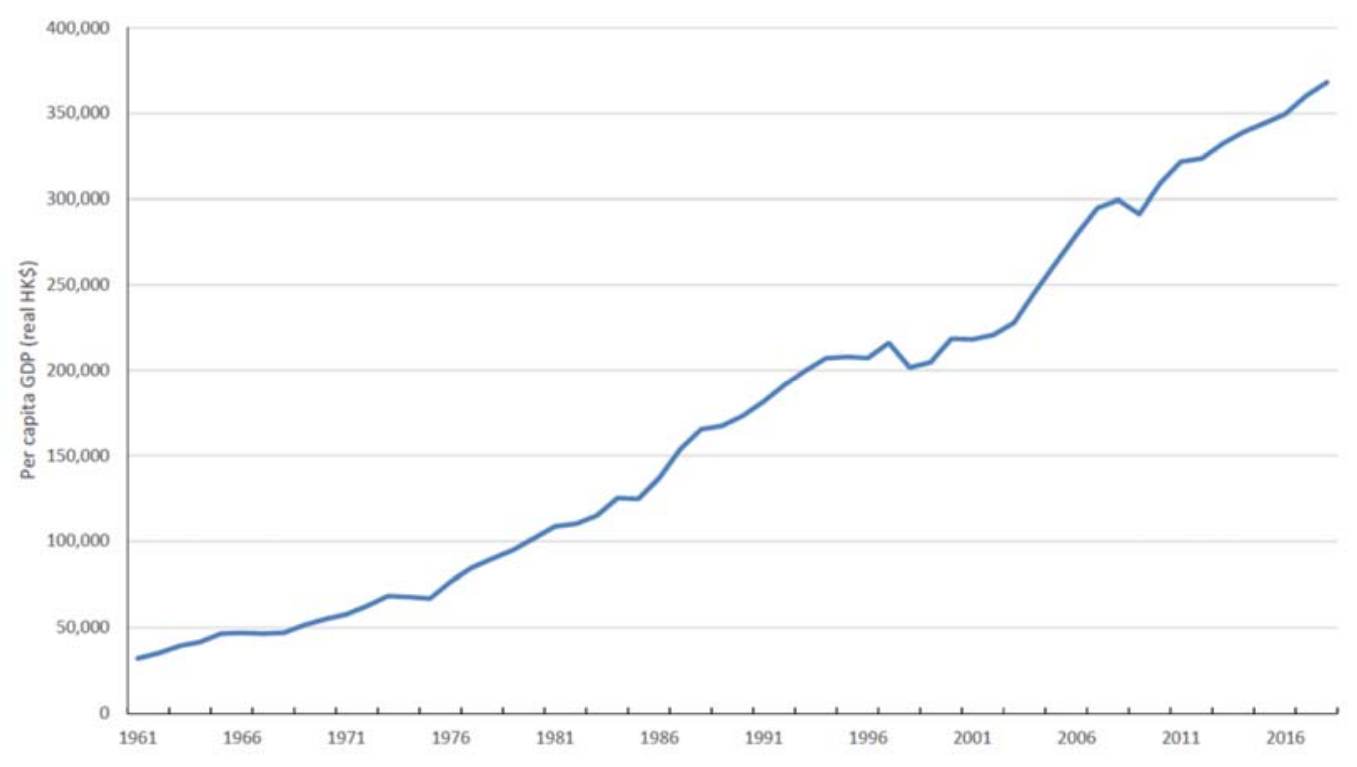

Figure 3b: Hong Kong wage index fails to catch up with the per capita GDP (real terms)

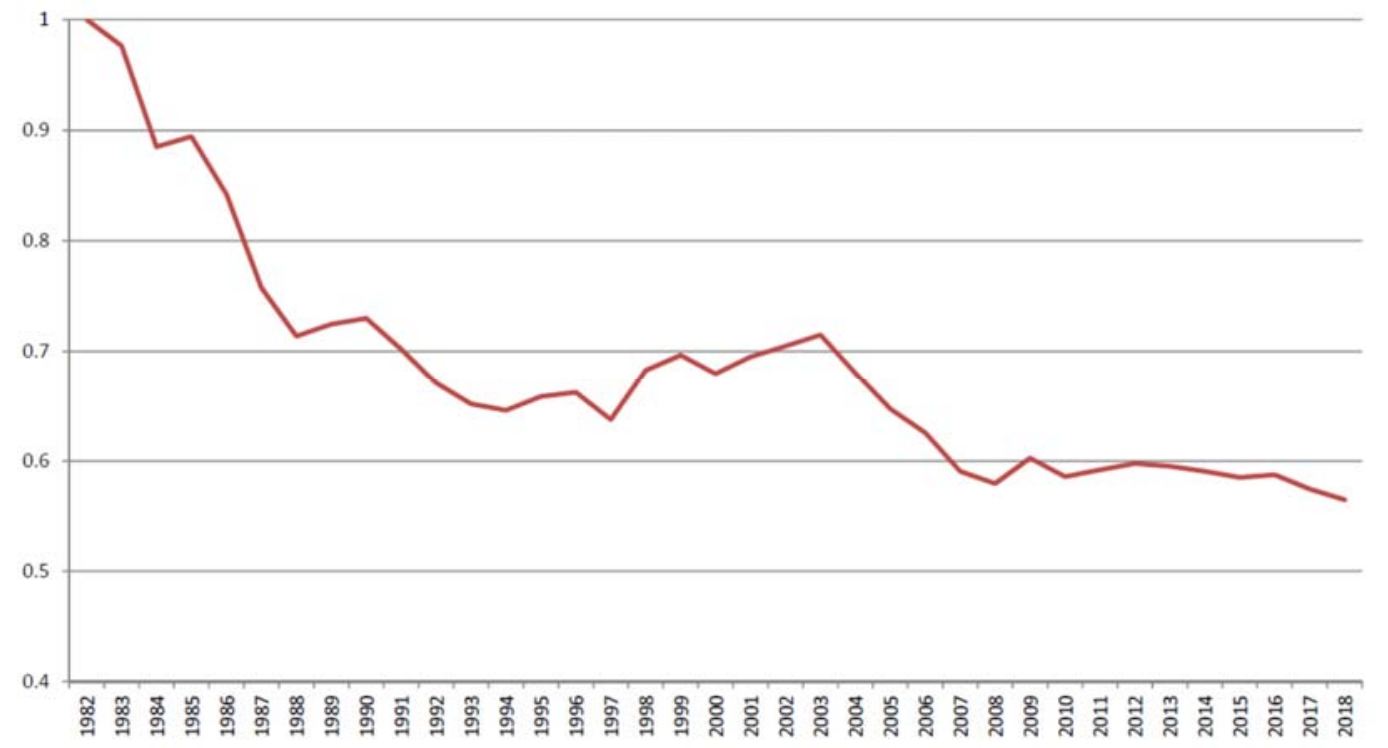


Figure 3c: Hong Kong Median household income (MHI) and wage index fail to catch up with the per capita GDP after Return to China

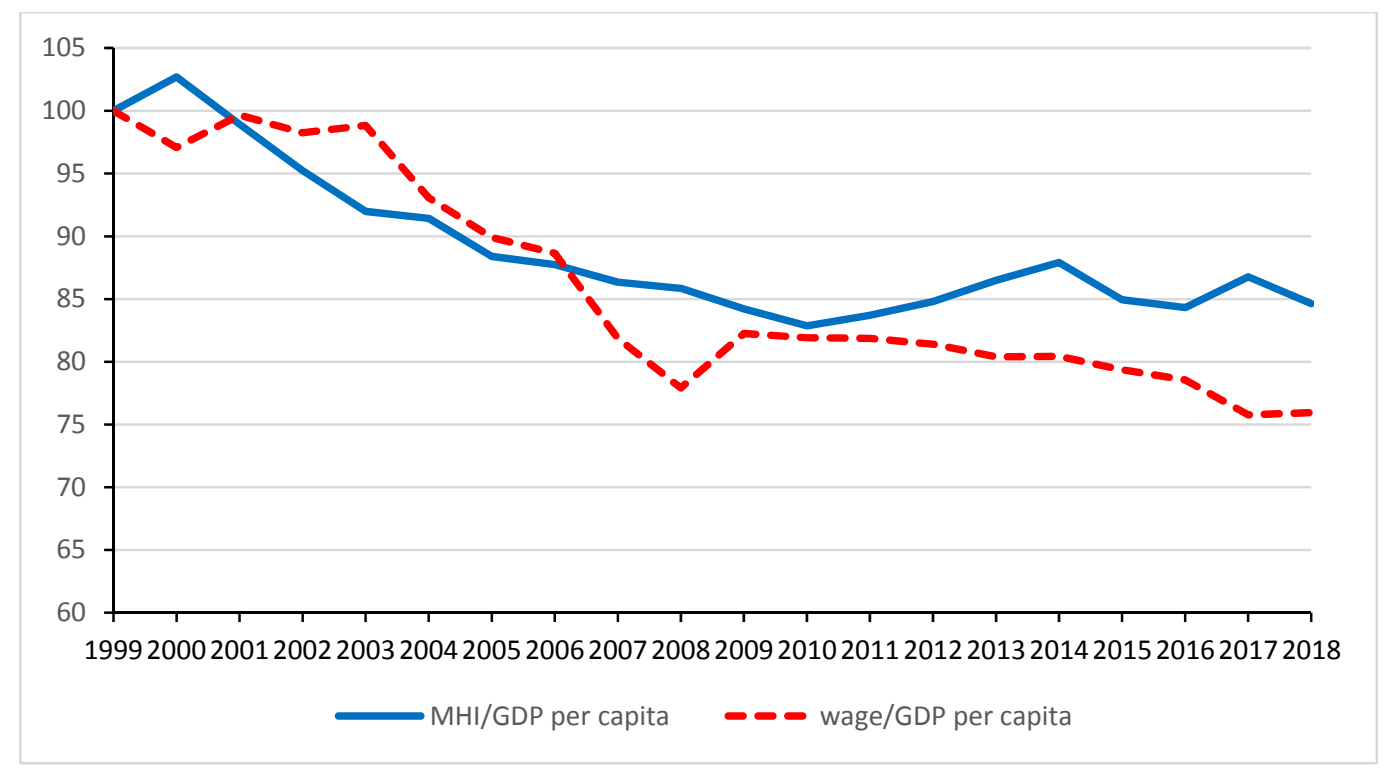


Figure 4a: Hong Kong Population and Life Expectancy increases over time

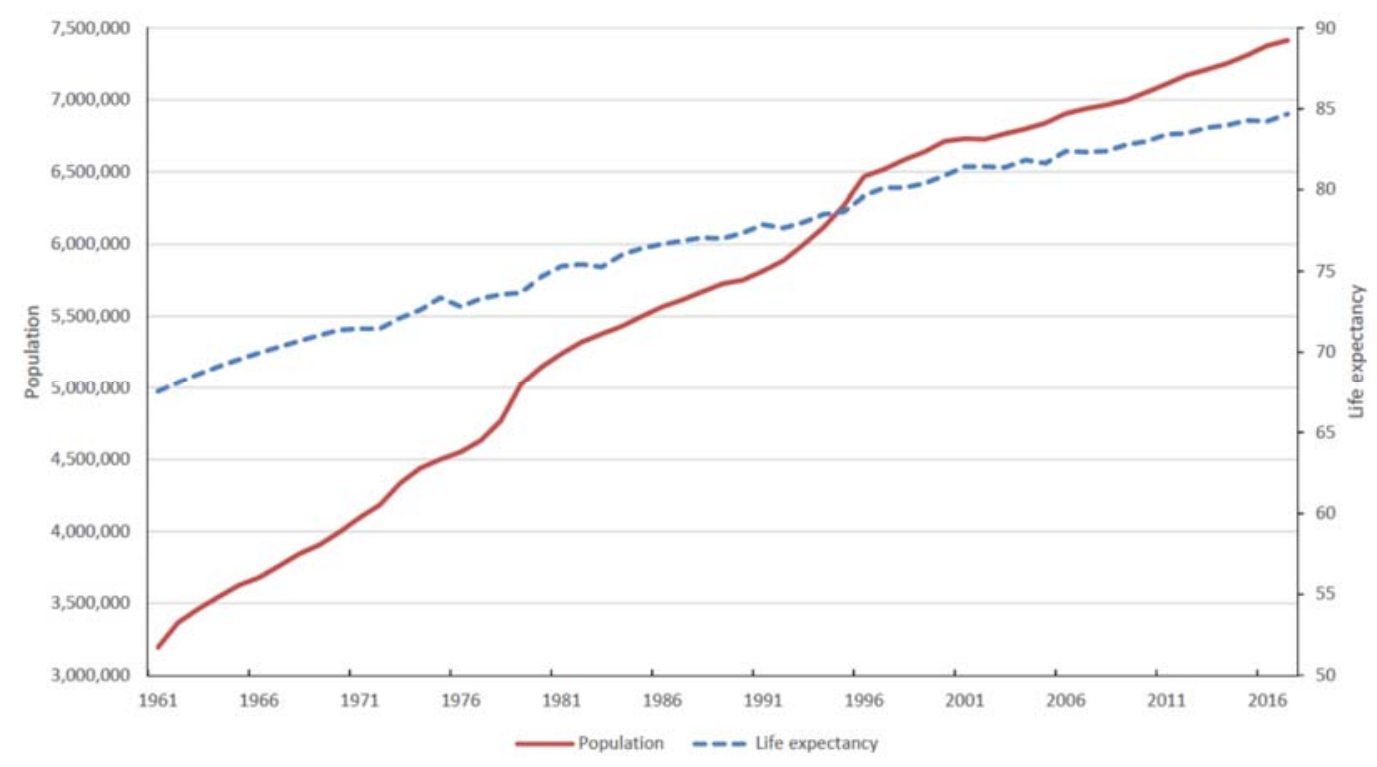

Figure 4b: Composition of Hong Kong Households (by number of members within the household)

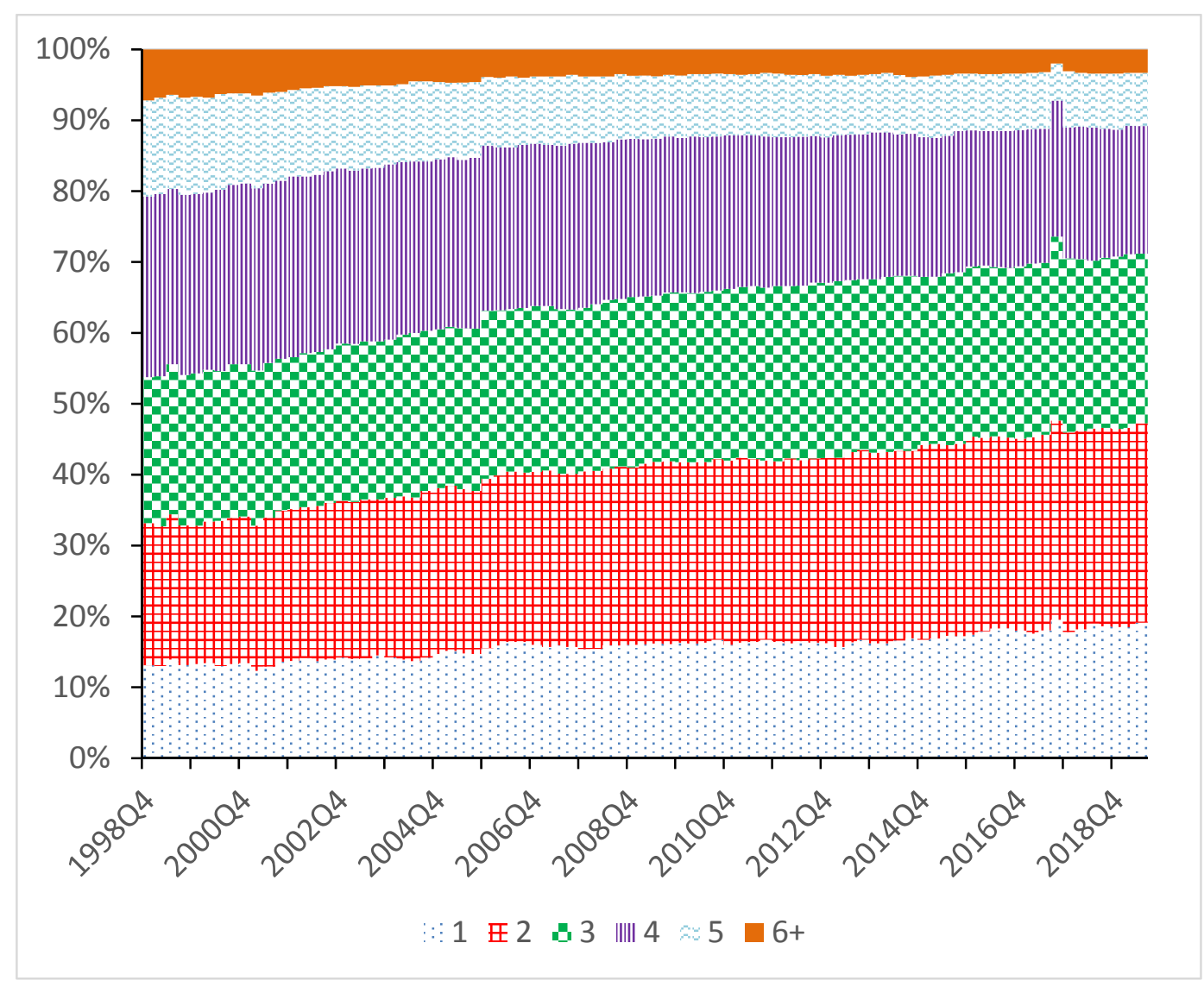


Figure 4c: Population densities across countries and regions

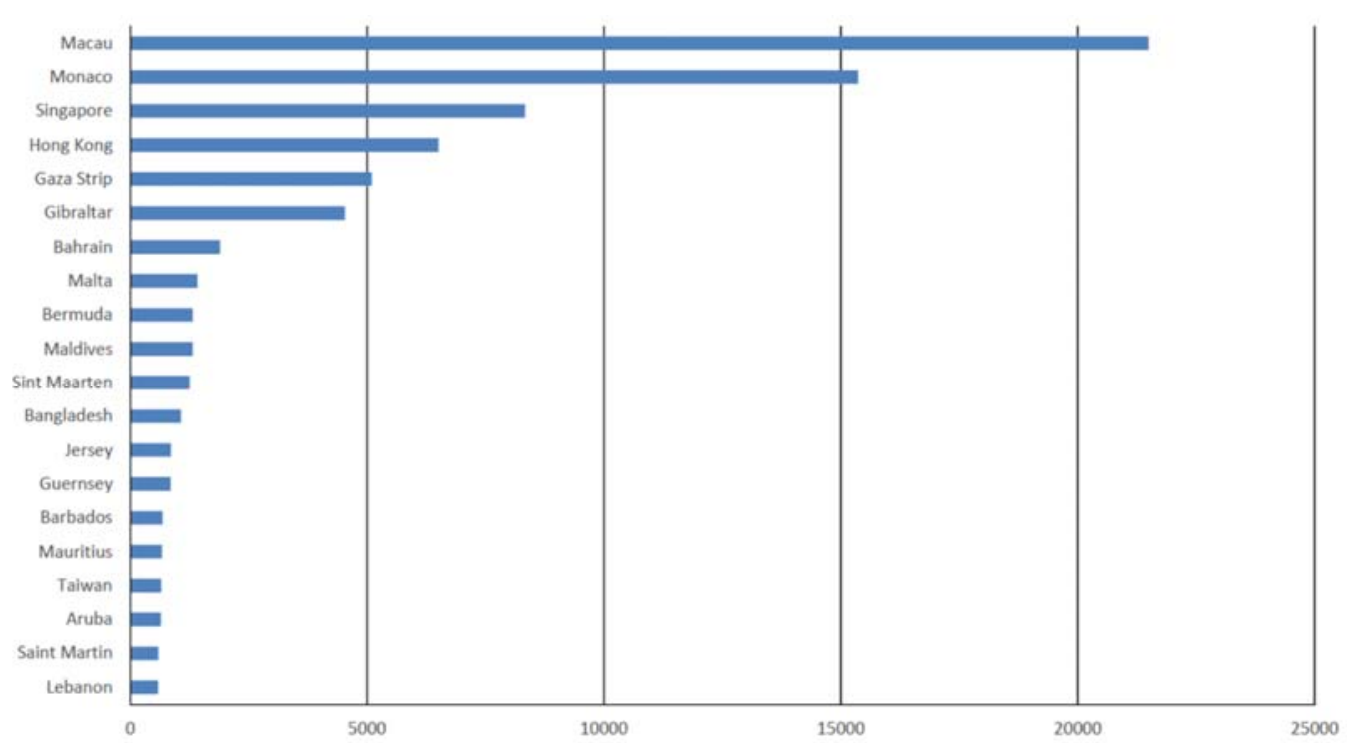

Source: $\mathrm{CIA}$

Figure 4d: New housing supply and real house price in Hong Kong

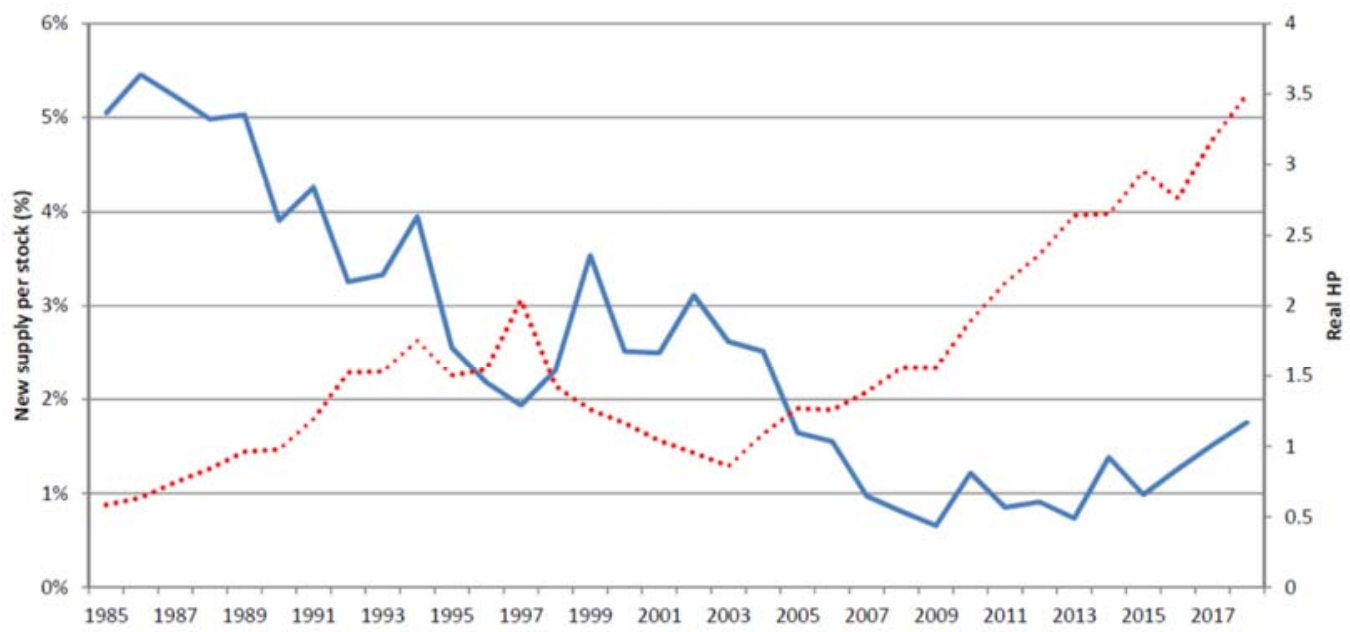


Figure 5a: Proportion of real estate-related tax as a percentage of total government revenue in Hong Kong

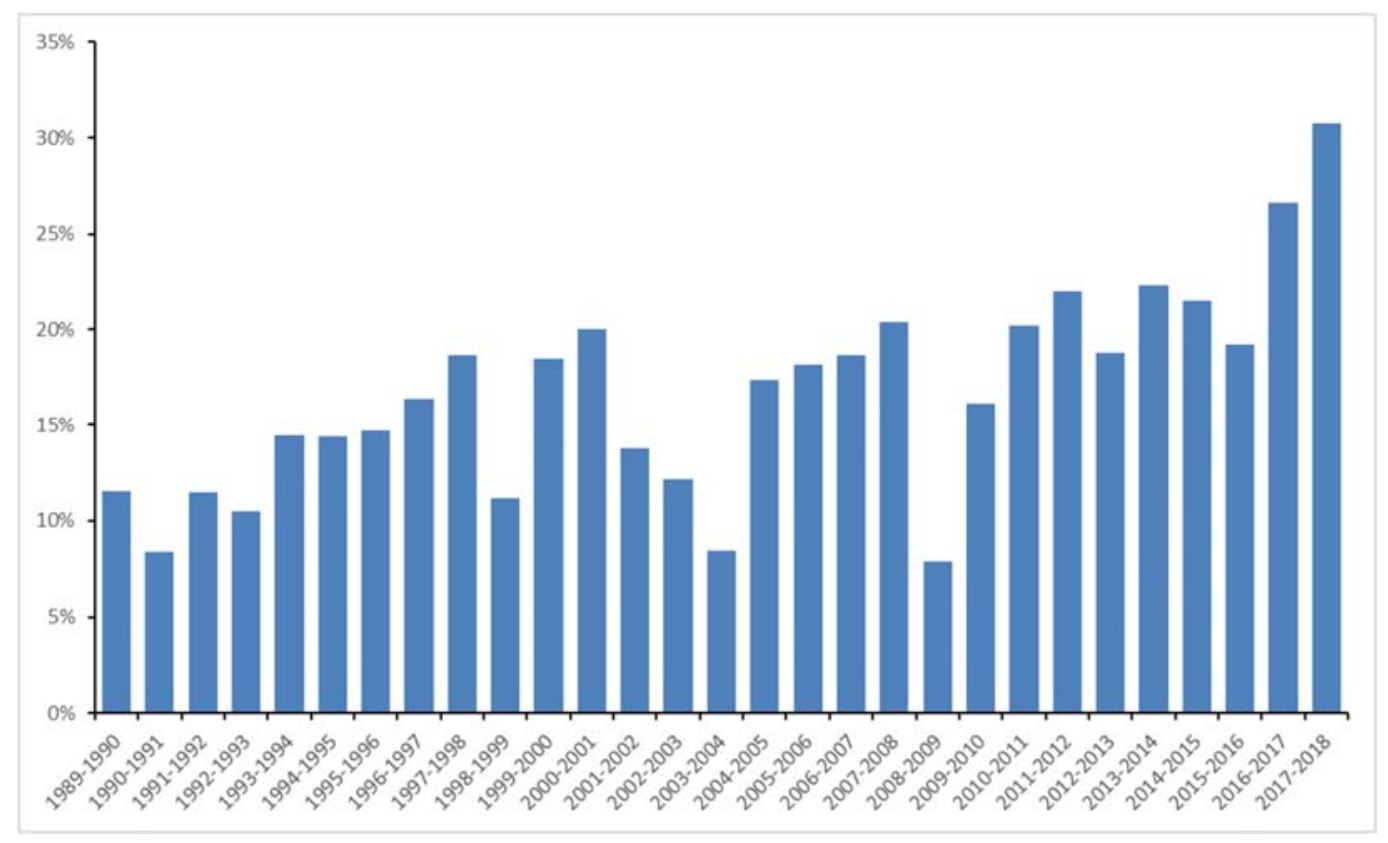

Figure 5b: Fiscal surplus-GDP and hypothetical fiscal surplus-GDP ratios of Hong Kong

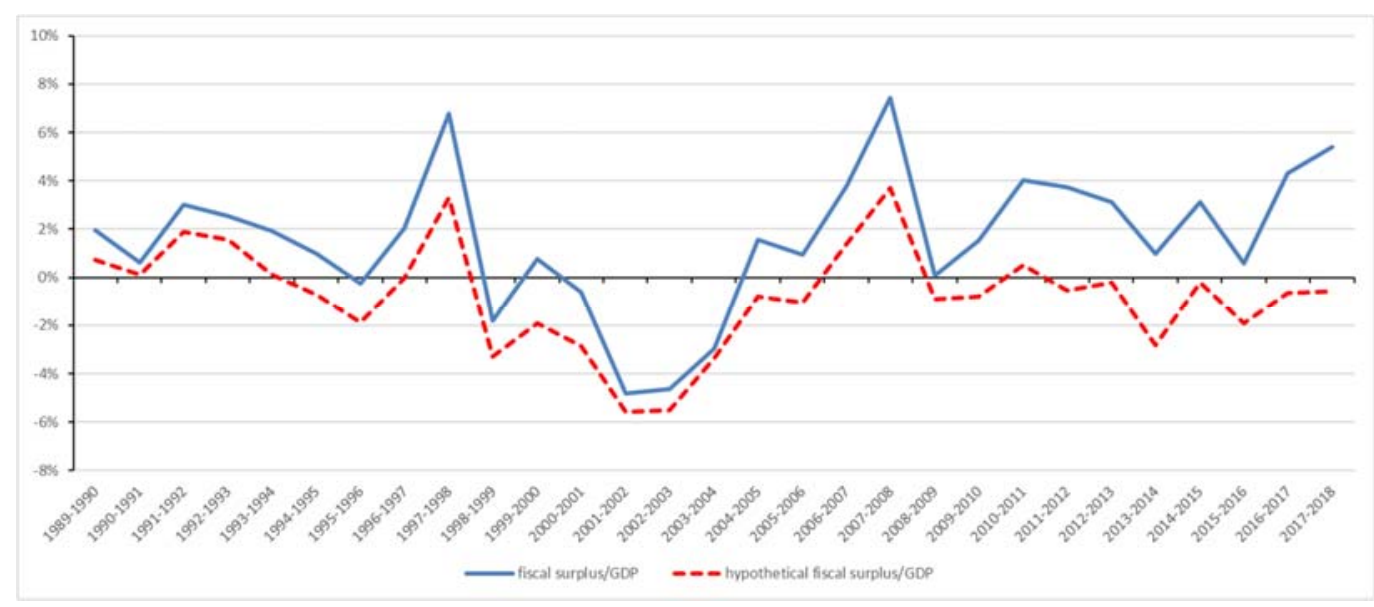

Note: The hypothetical fiscal surplus is the official fiscal surplus minus the land sale revenue 
Figure 5c: The composition of the Hong Kong government expenditure

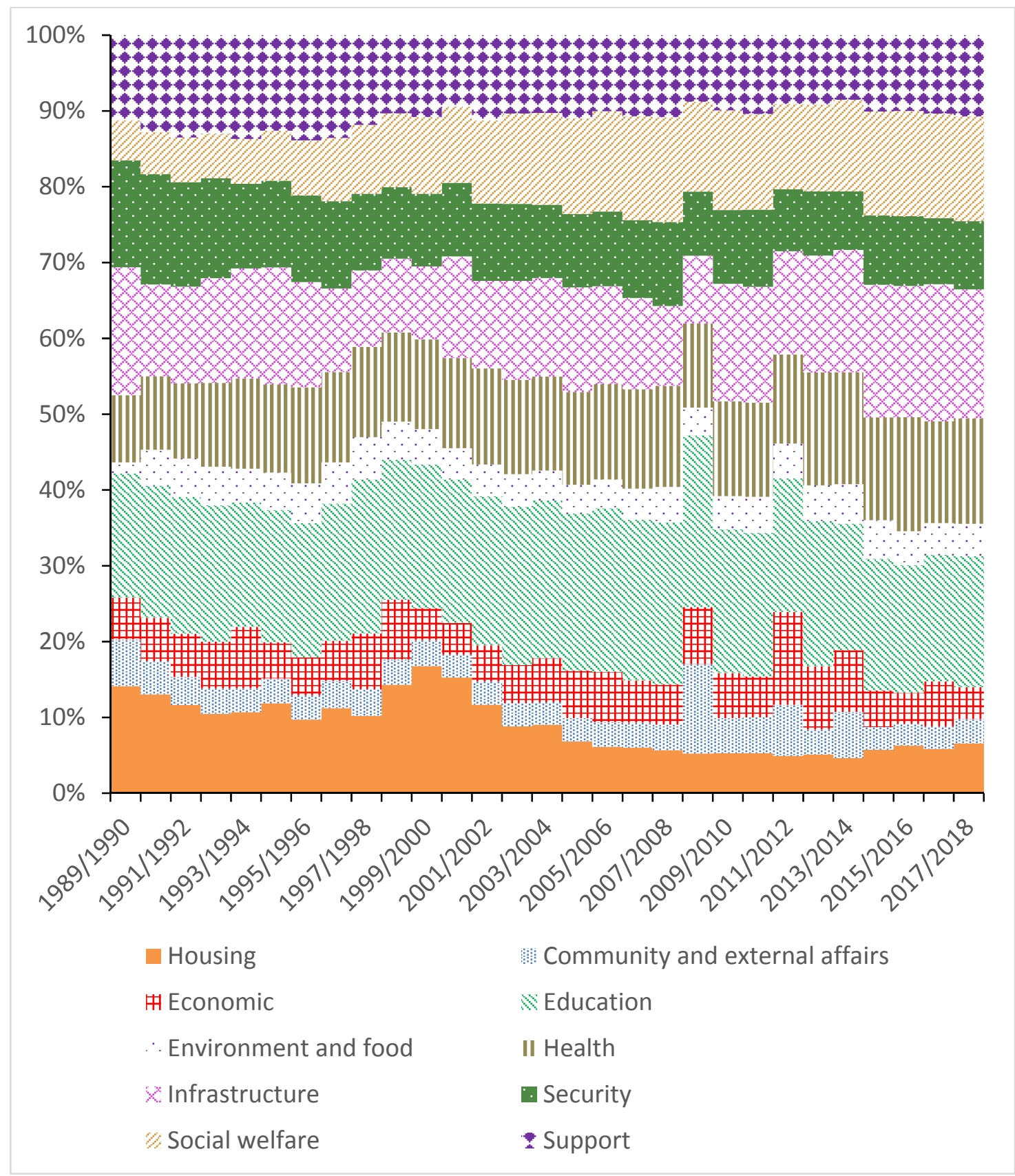


Figure 6 Age Composition of the Immigrants from Mainland China

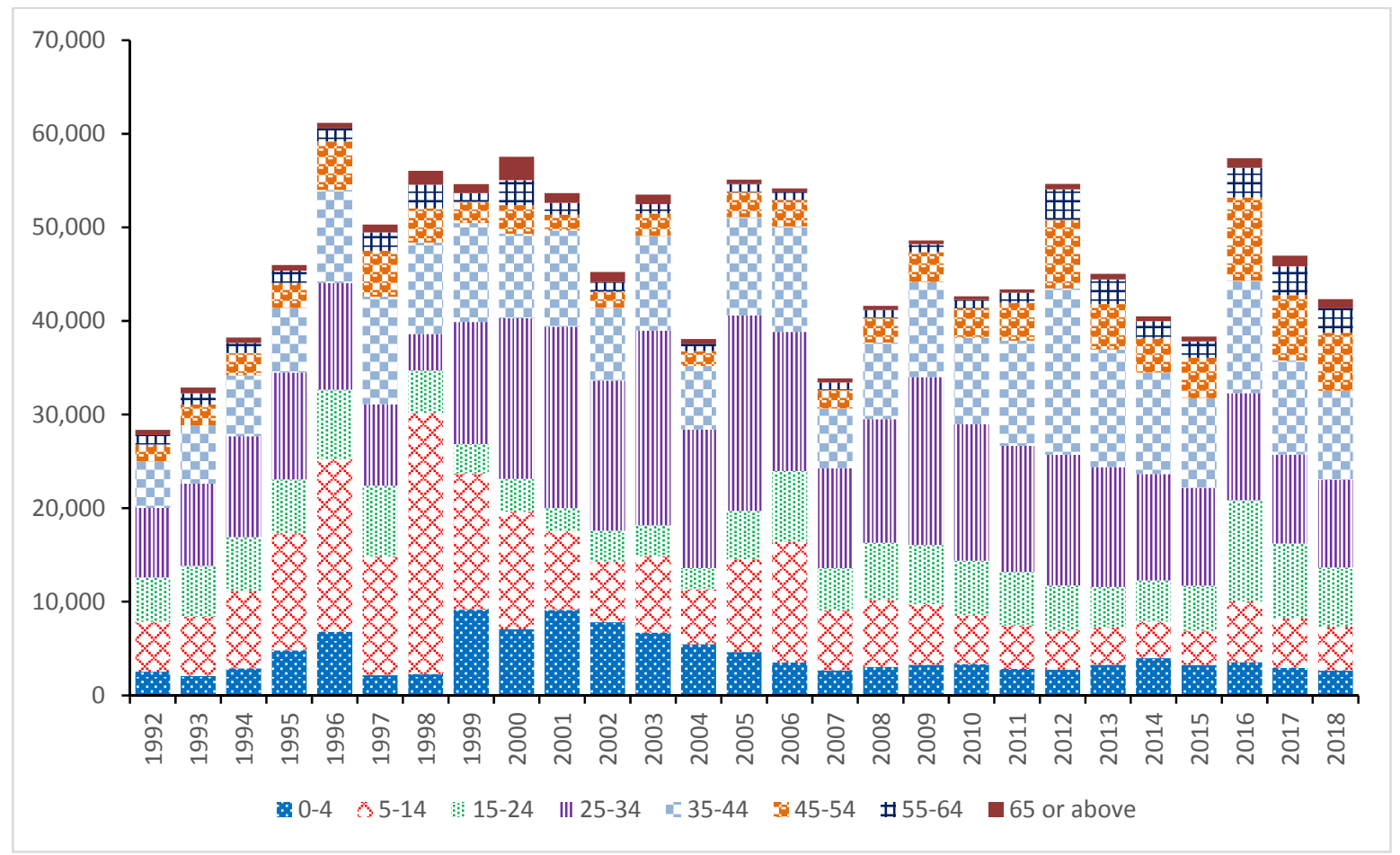


Figure 7a. Trend component of real export of Hong Kong estimated by different filters

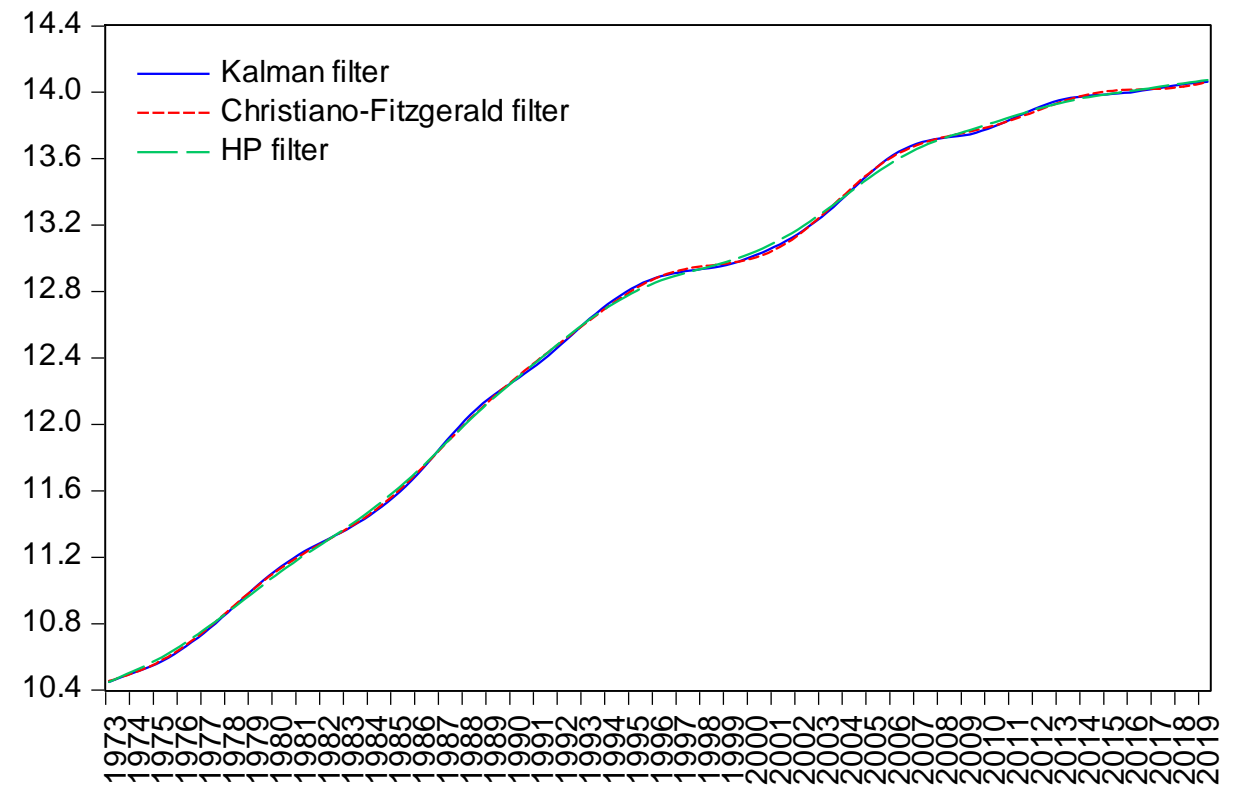


Figure 7b. Comparison between different filters: an example
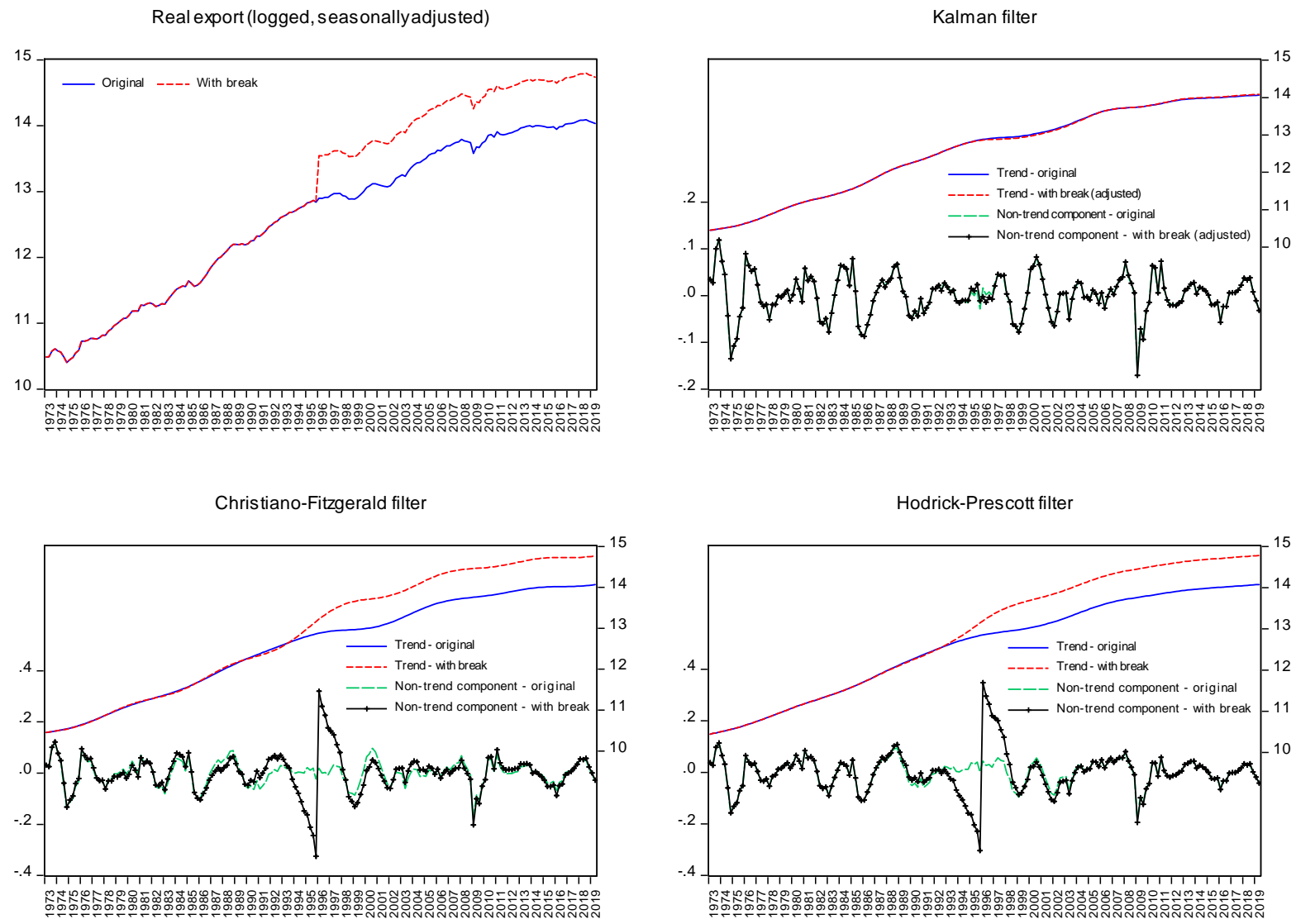
Figure 8a. Decomposition of Hong Kong real GDP growth rate
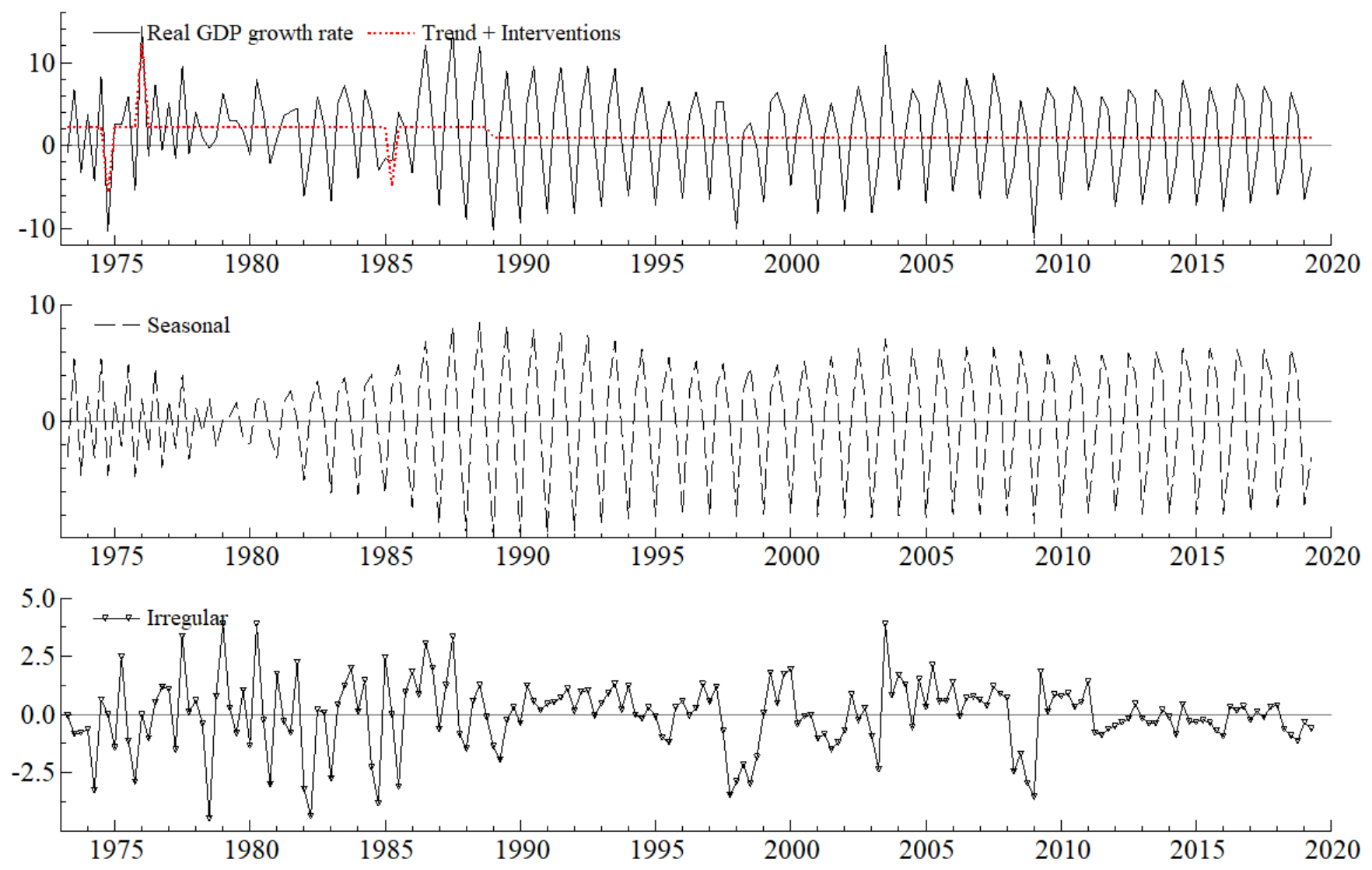
Figure 8b. Decomposition of China real GDP growth rate
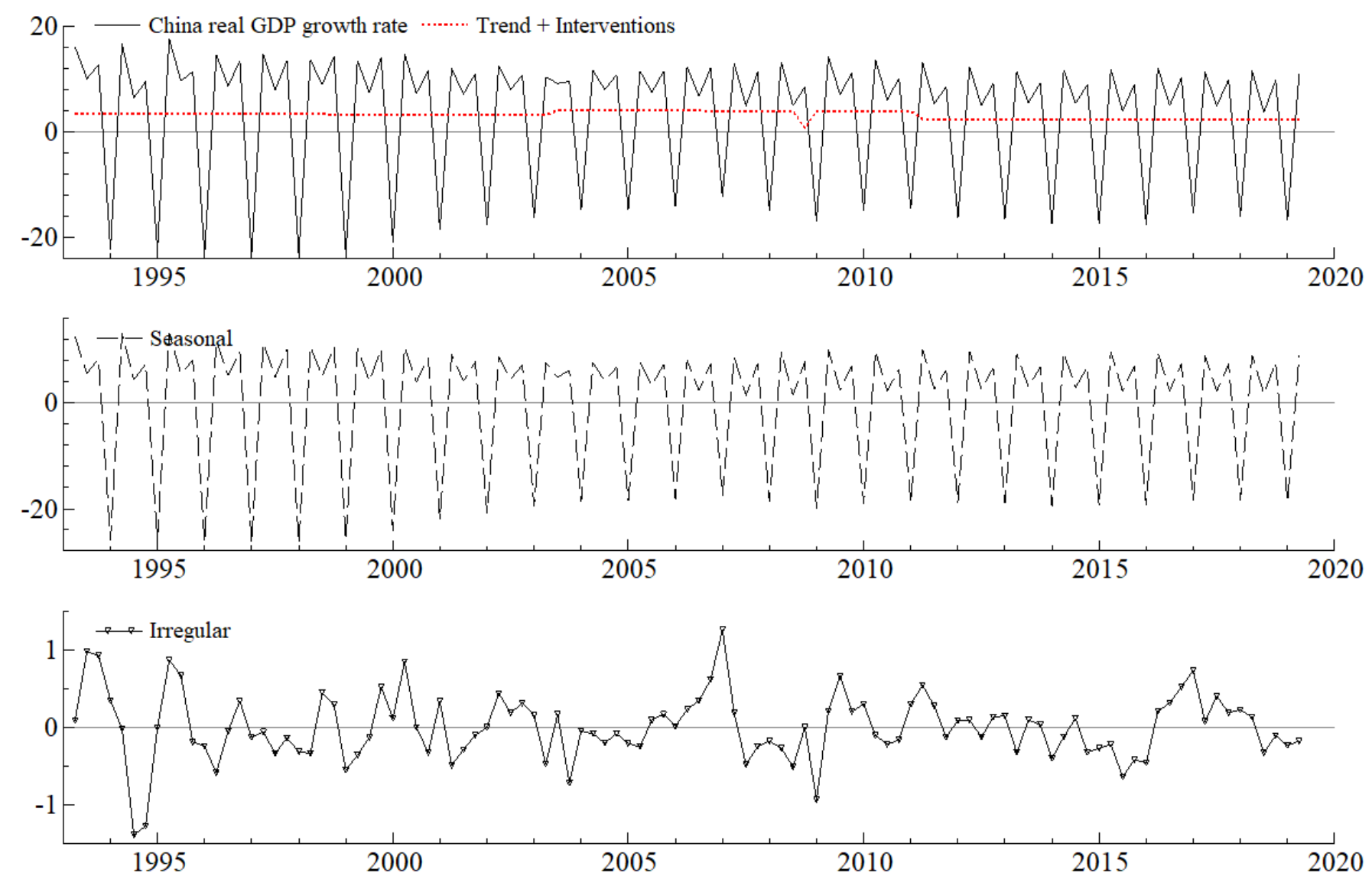
Figure 8c. Decomposition of Hong Kong real GDP per capita growth rate
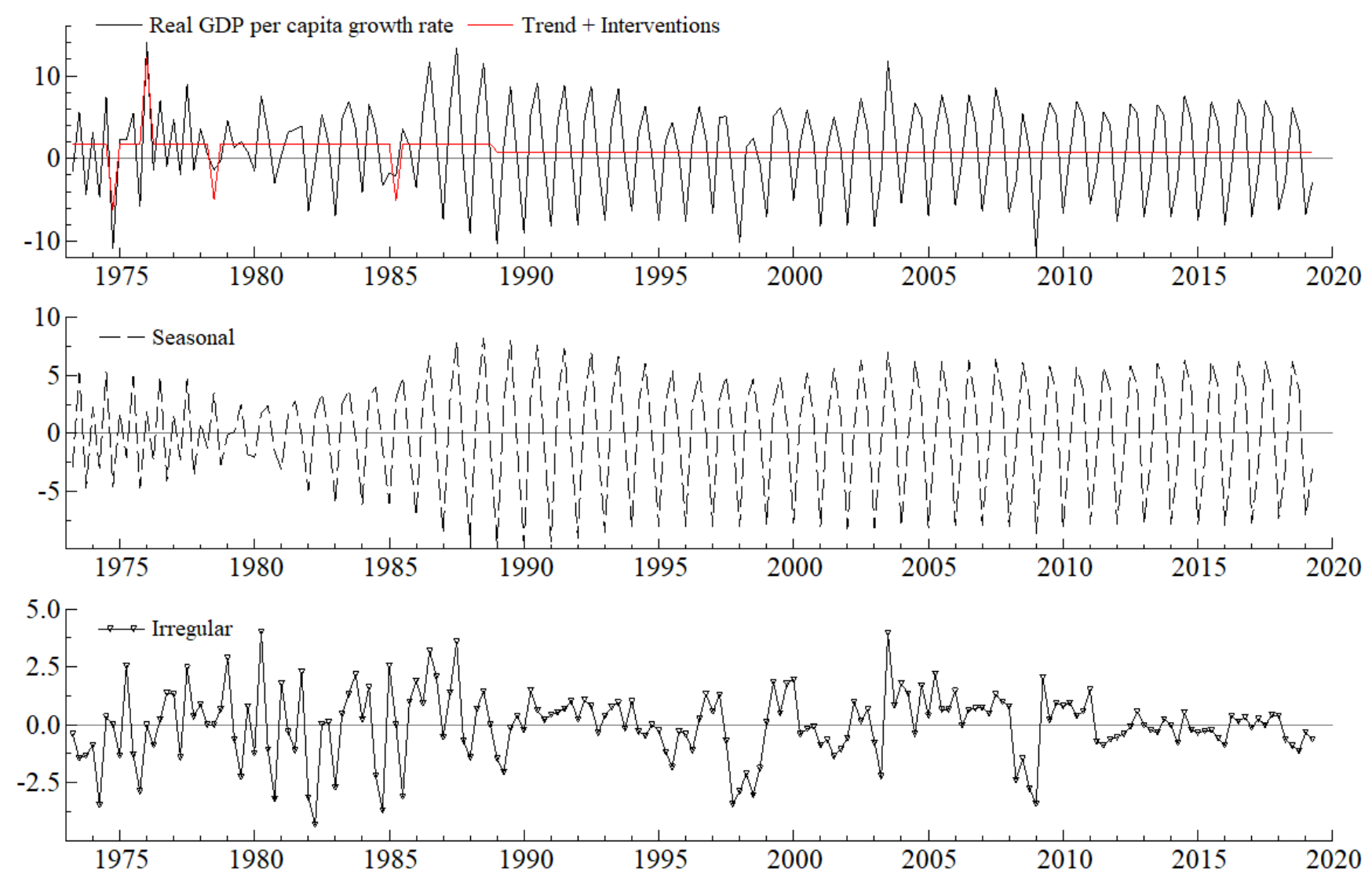
Figure 8d. Decomposition of Hong Kong unemployment rate
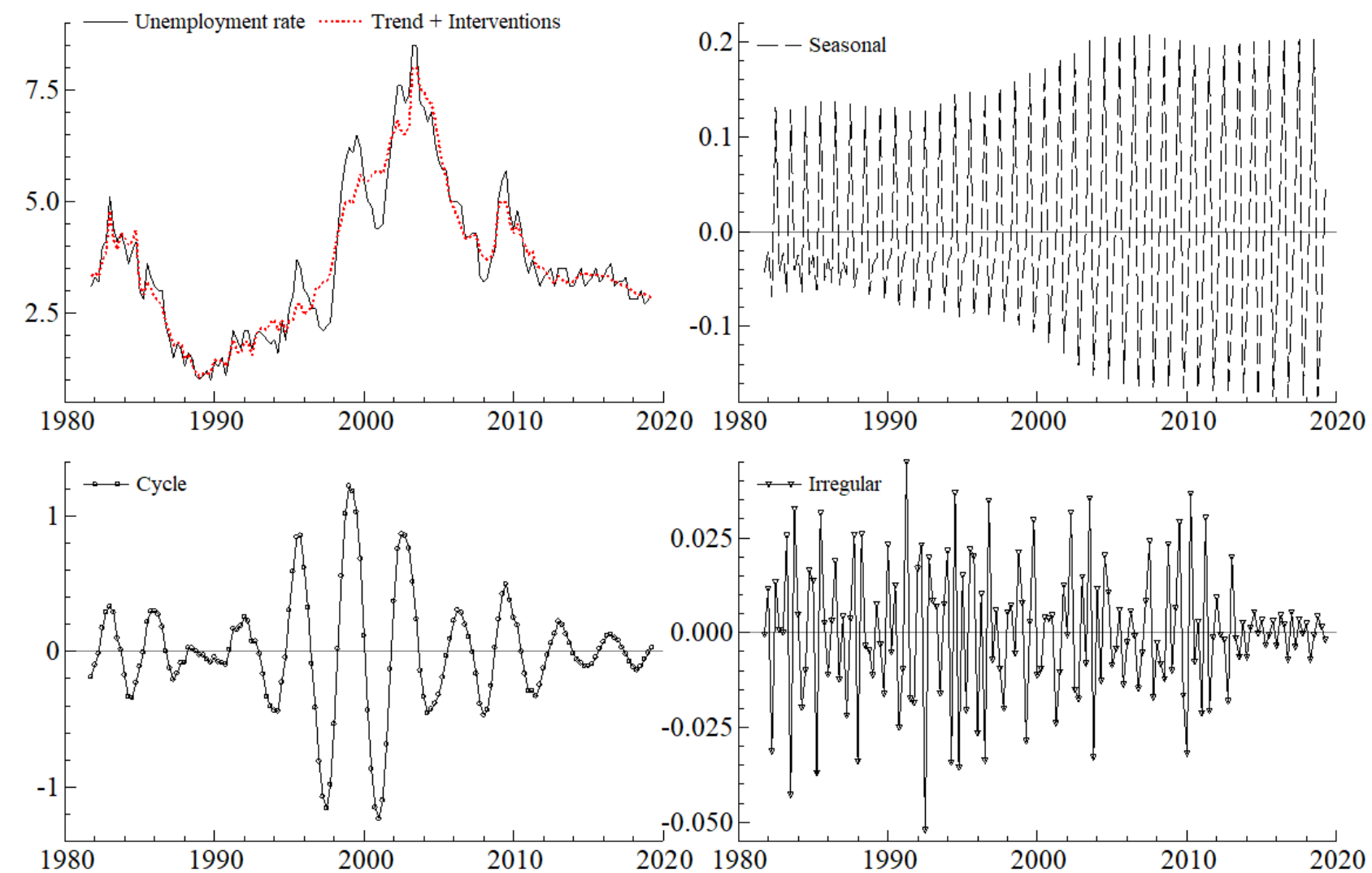
Figure 8e. Decomposition of China unemployment rate
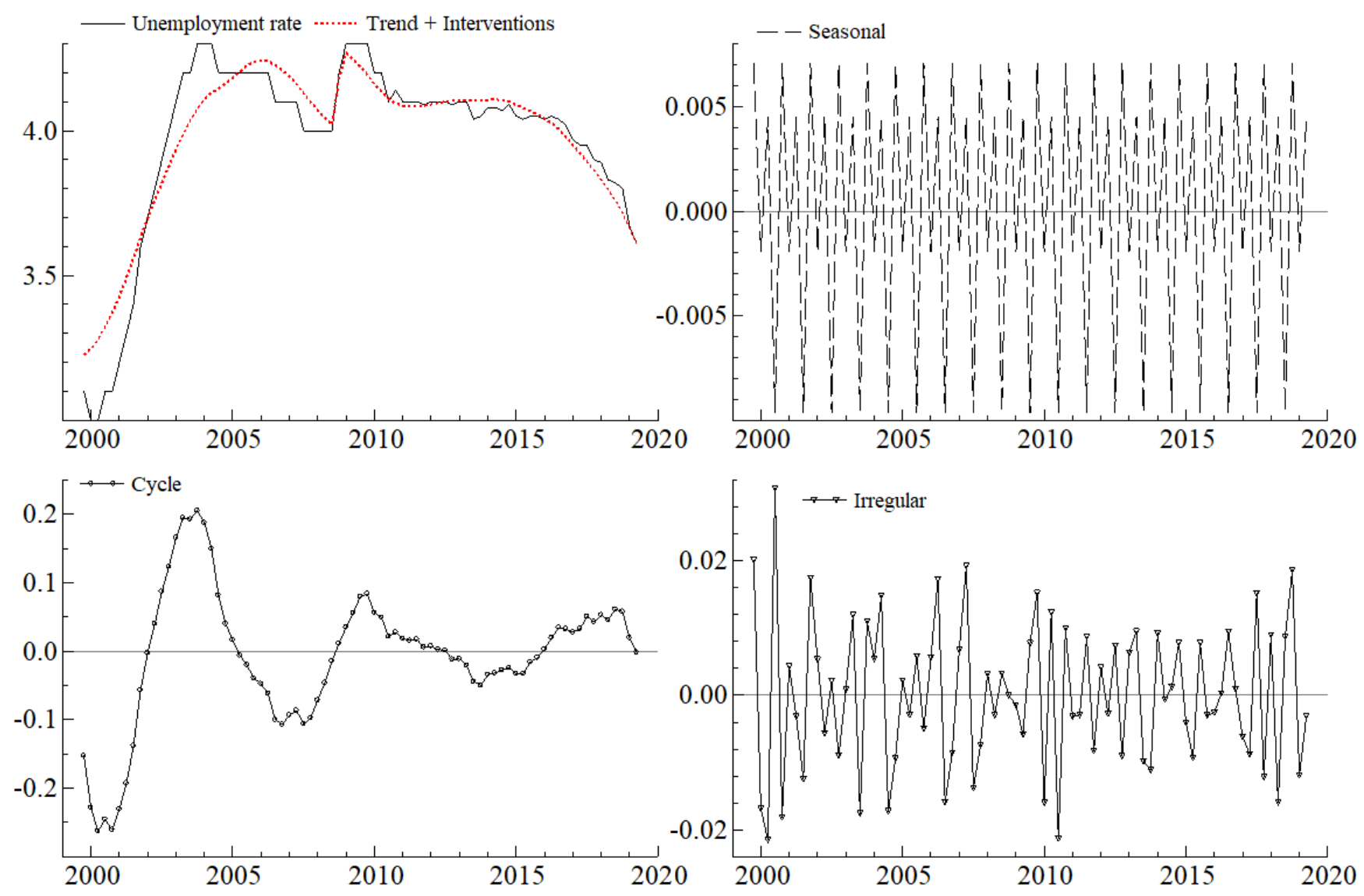
Figure 8f. Decomposition of Hong Kong real trade growth rate
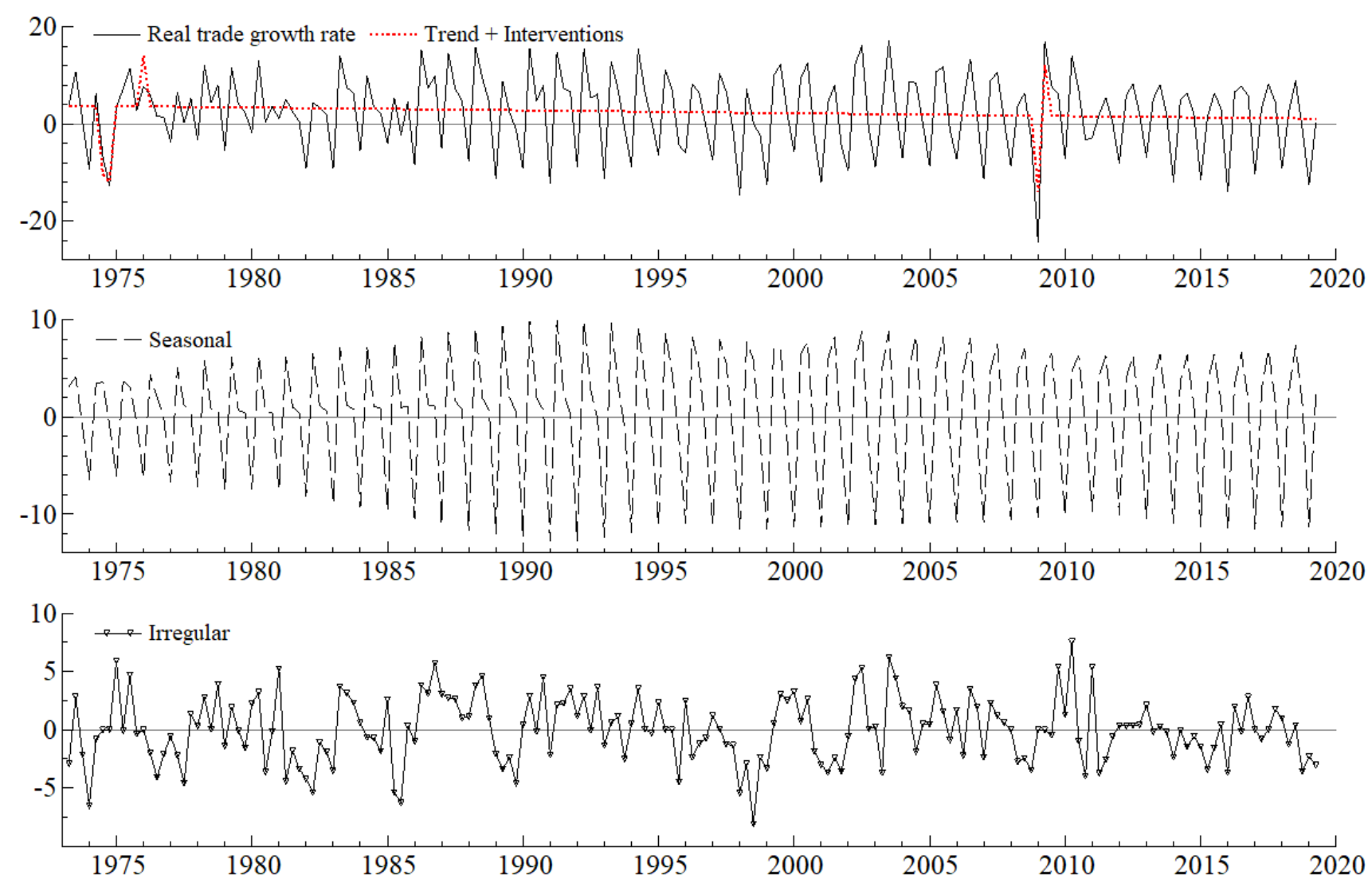
Figure 8g. Decomposition of Hong Kong real export growth rate
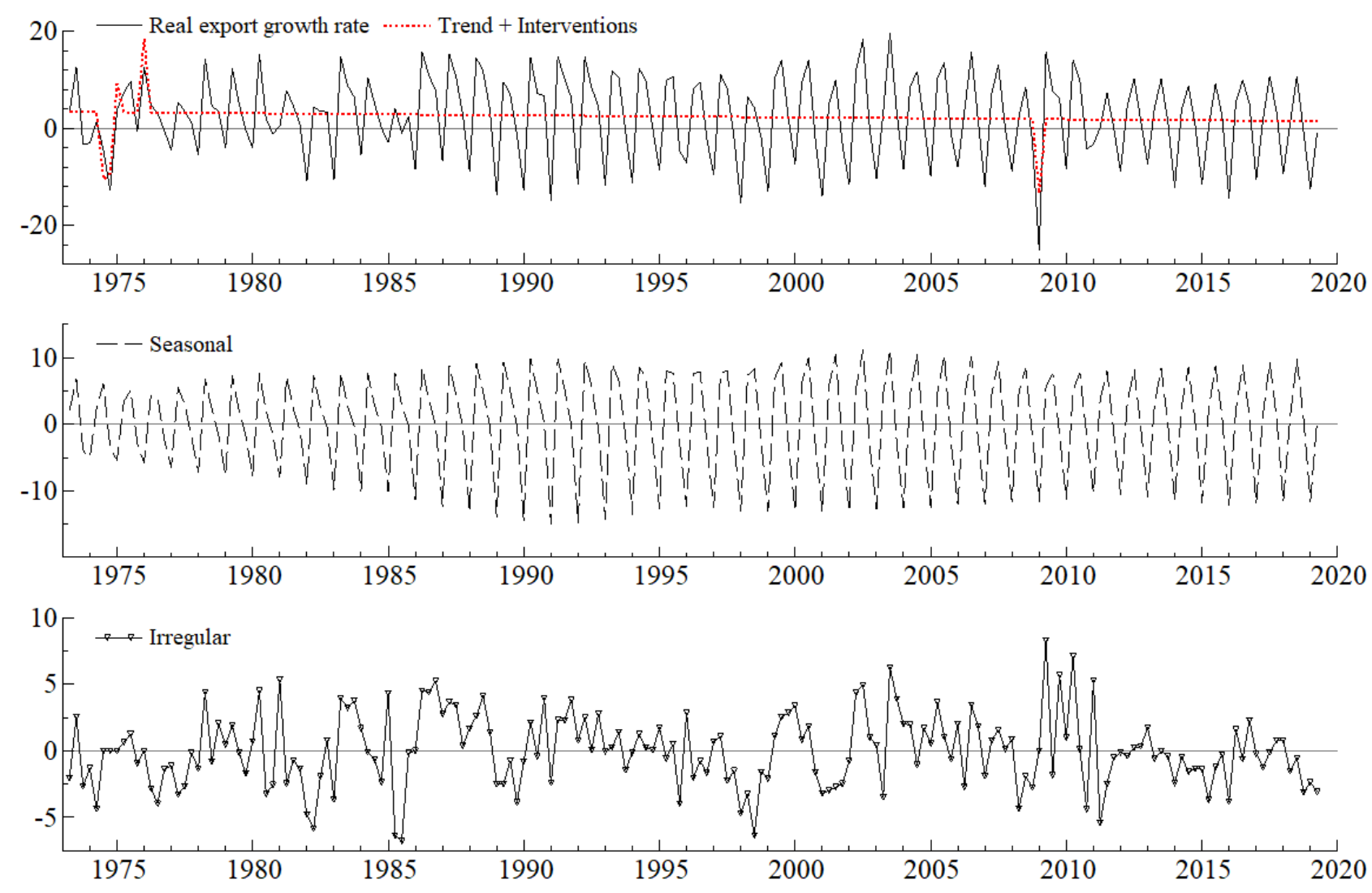
Figure 8h. Decomposition of Hong Kong real import growth rate
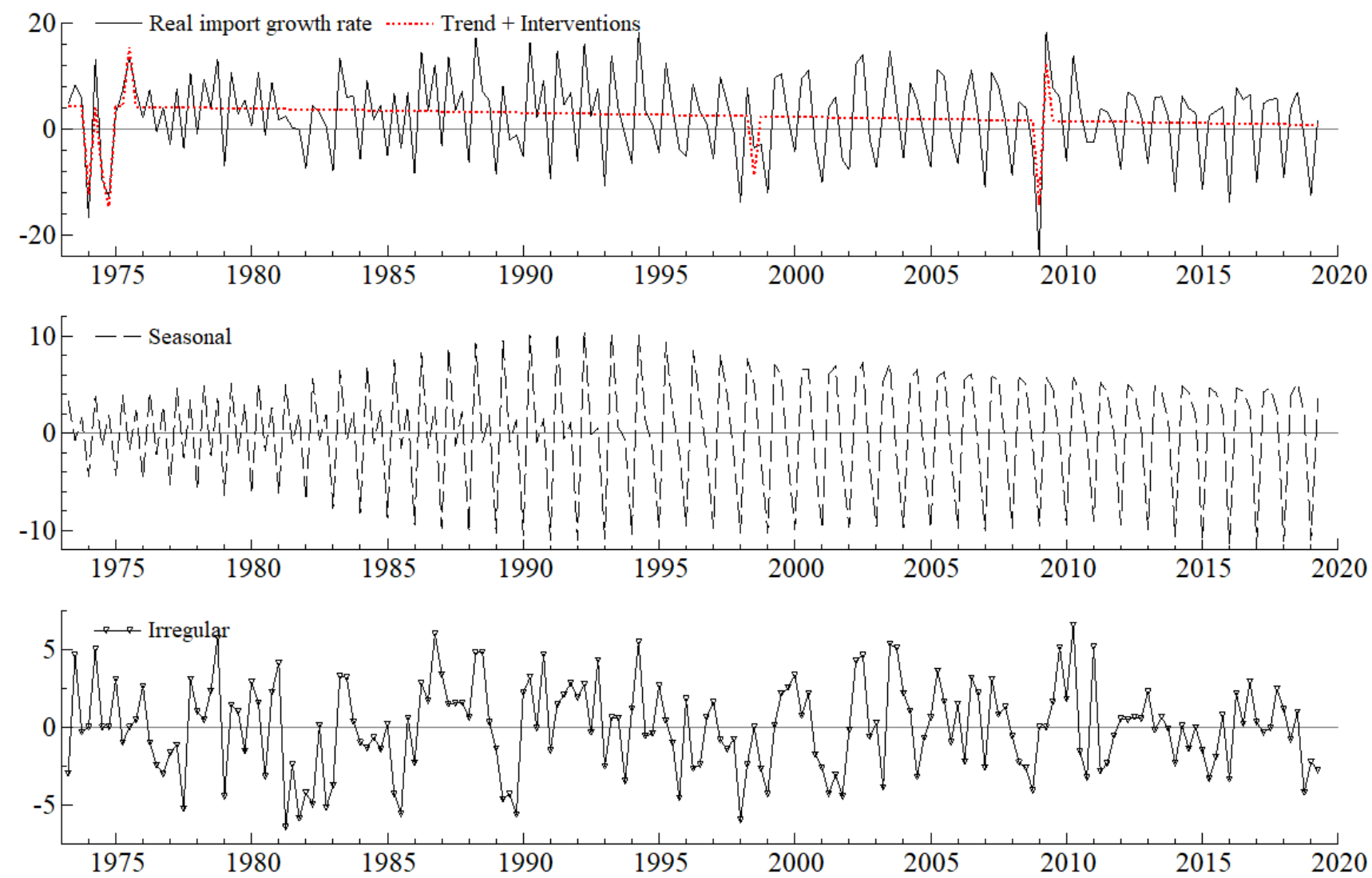
Figure 8i. Decomposition of Hong Kong real consumption expenditure growth rate
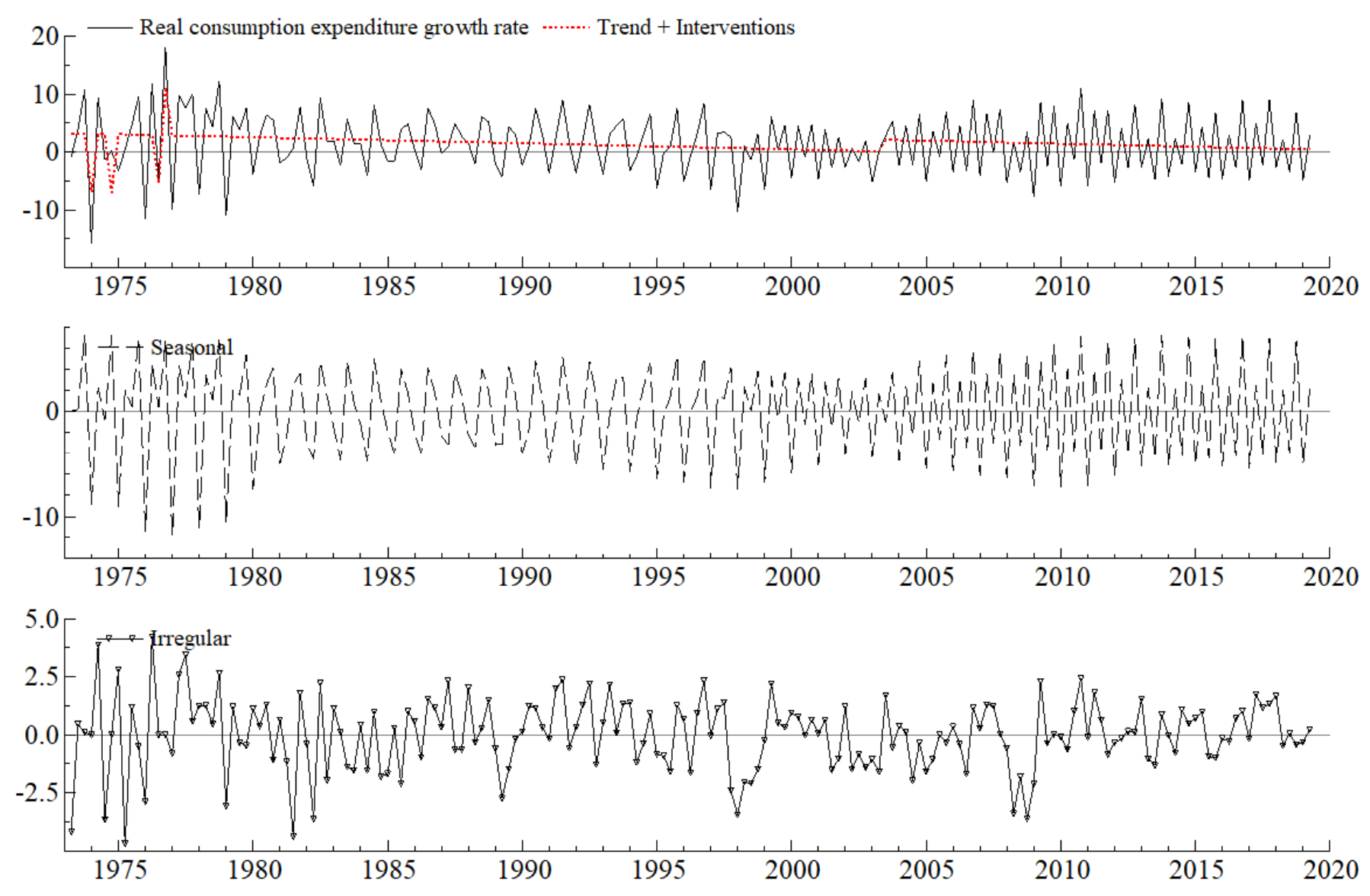
Figure 8j. Decomposition of Hong Kong real investment growth rate
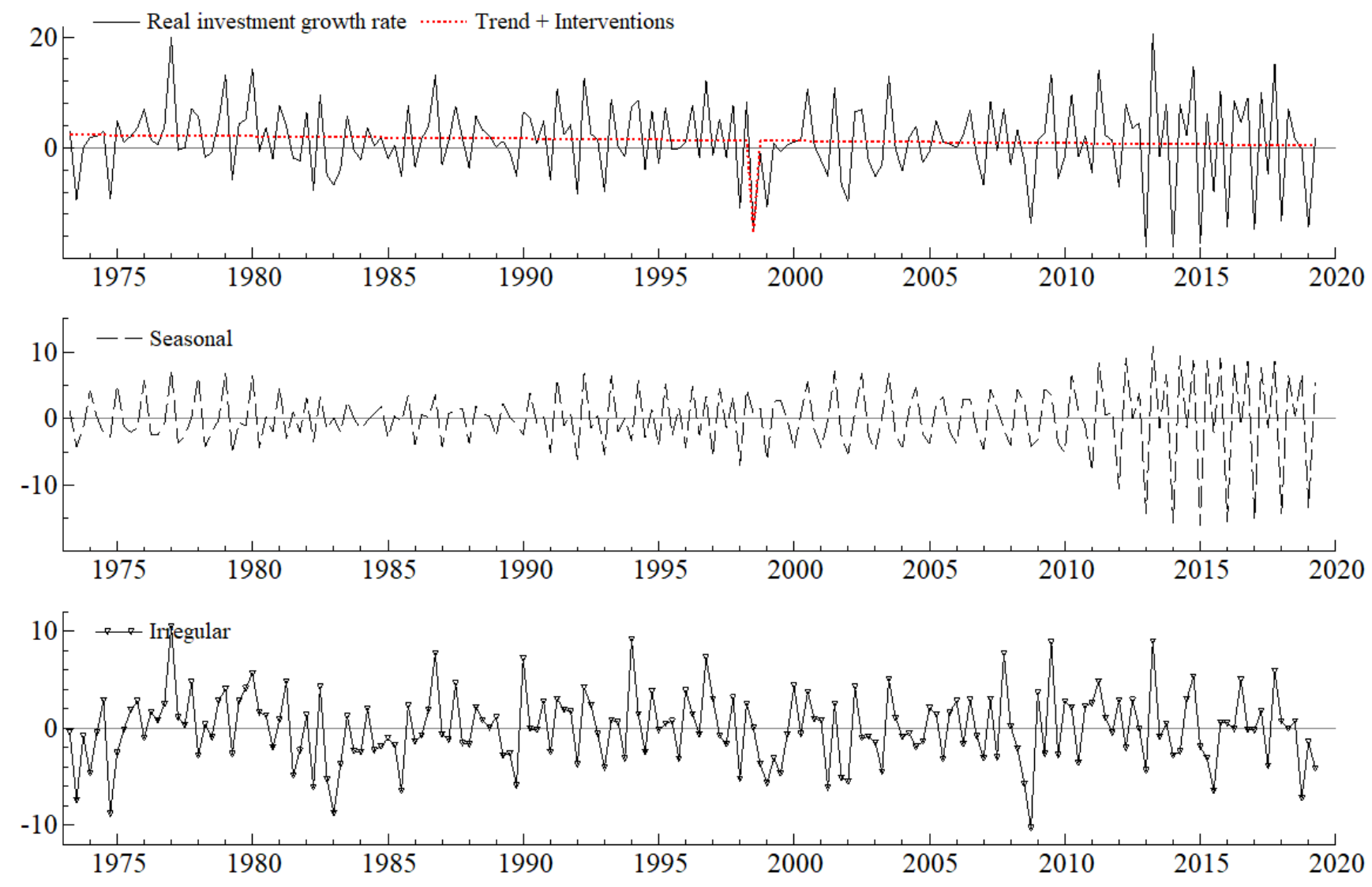
Figure 8k. Decomposition of Hong Kong real wage growth rate
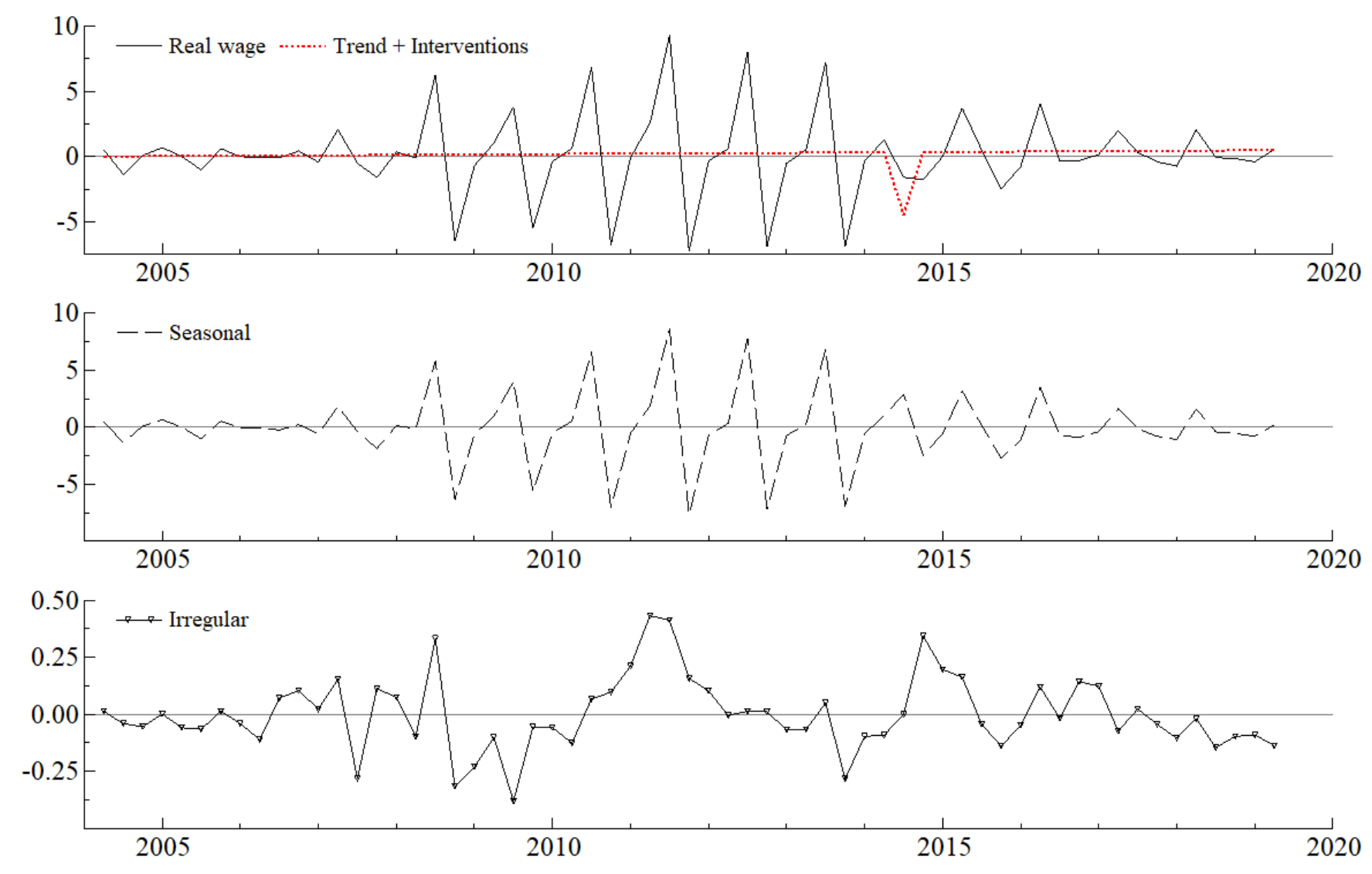
Figure 8l. Decomposition of Hong Kong real government spending growth rate
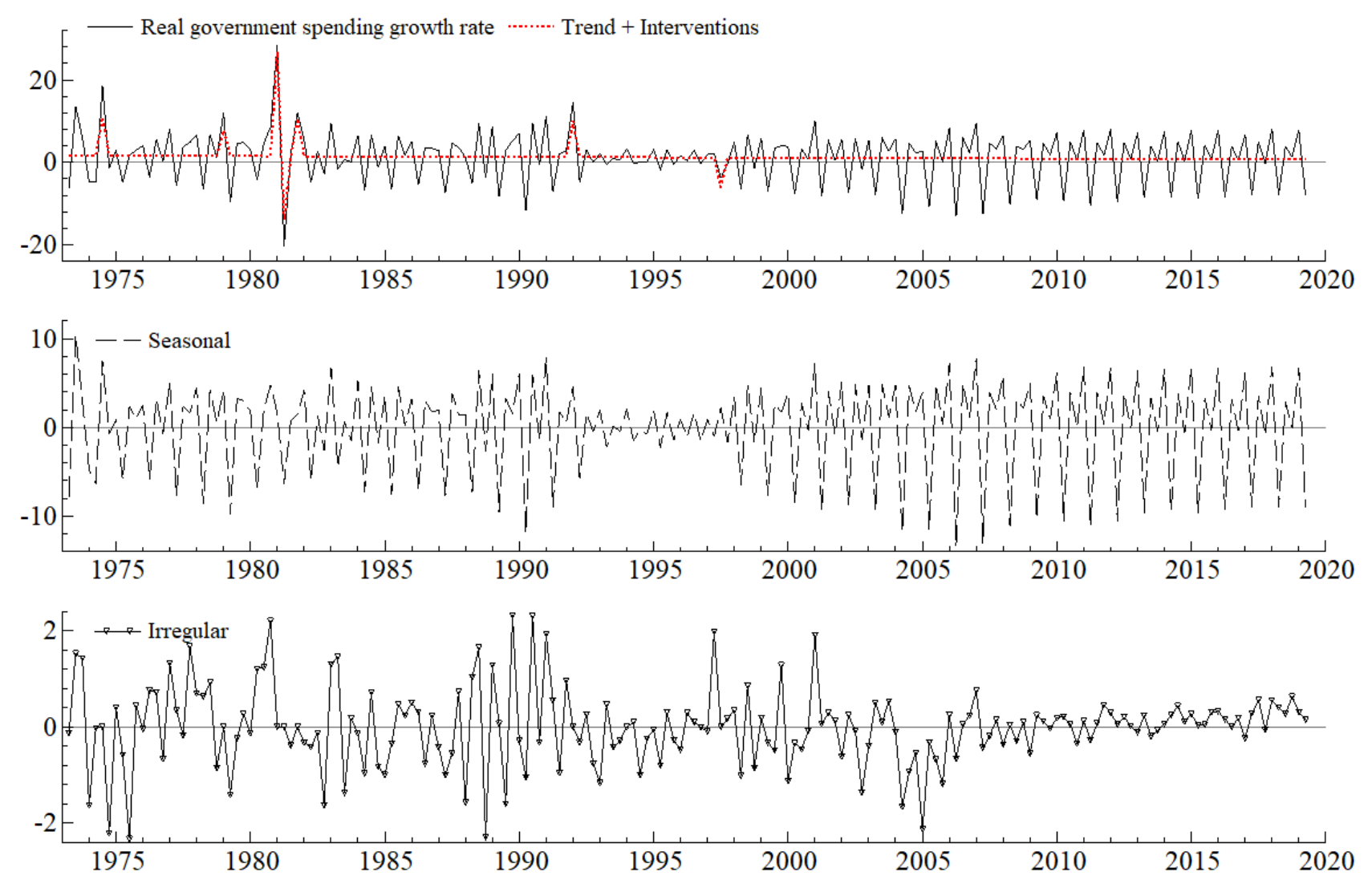
Figure 8m. Decomposition of Hong Kong real housing price growth rate
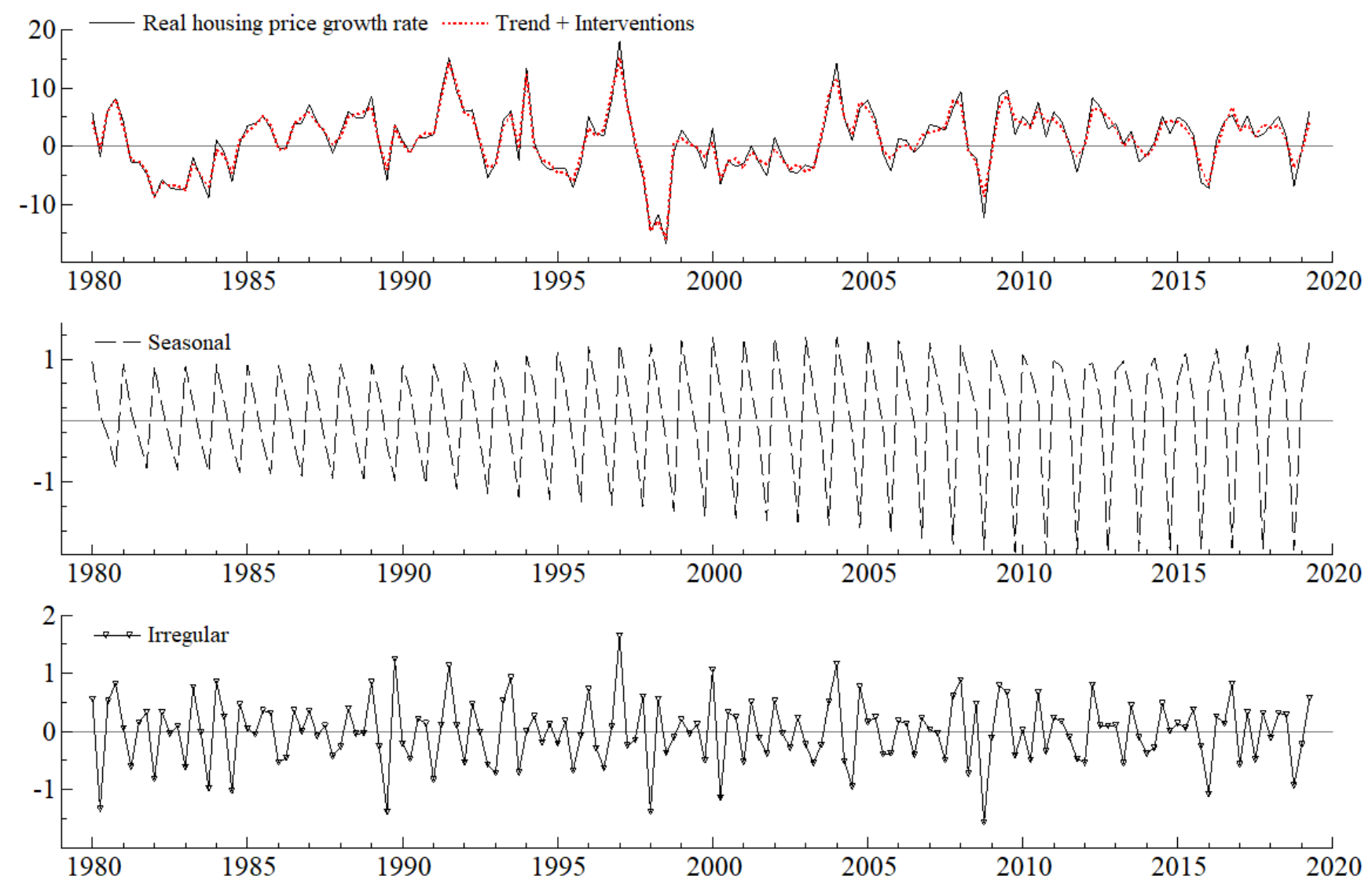
Figure 8n. Decomposition of Hong Kong real housing rent growth rate
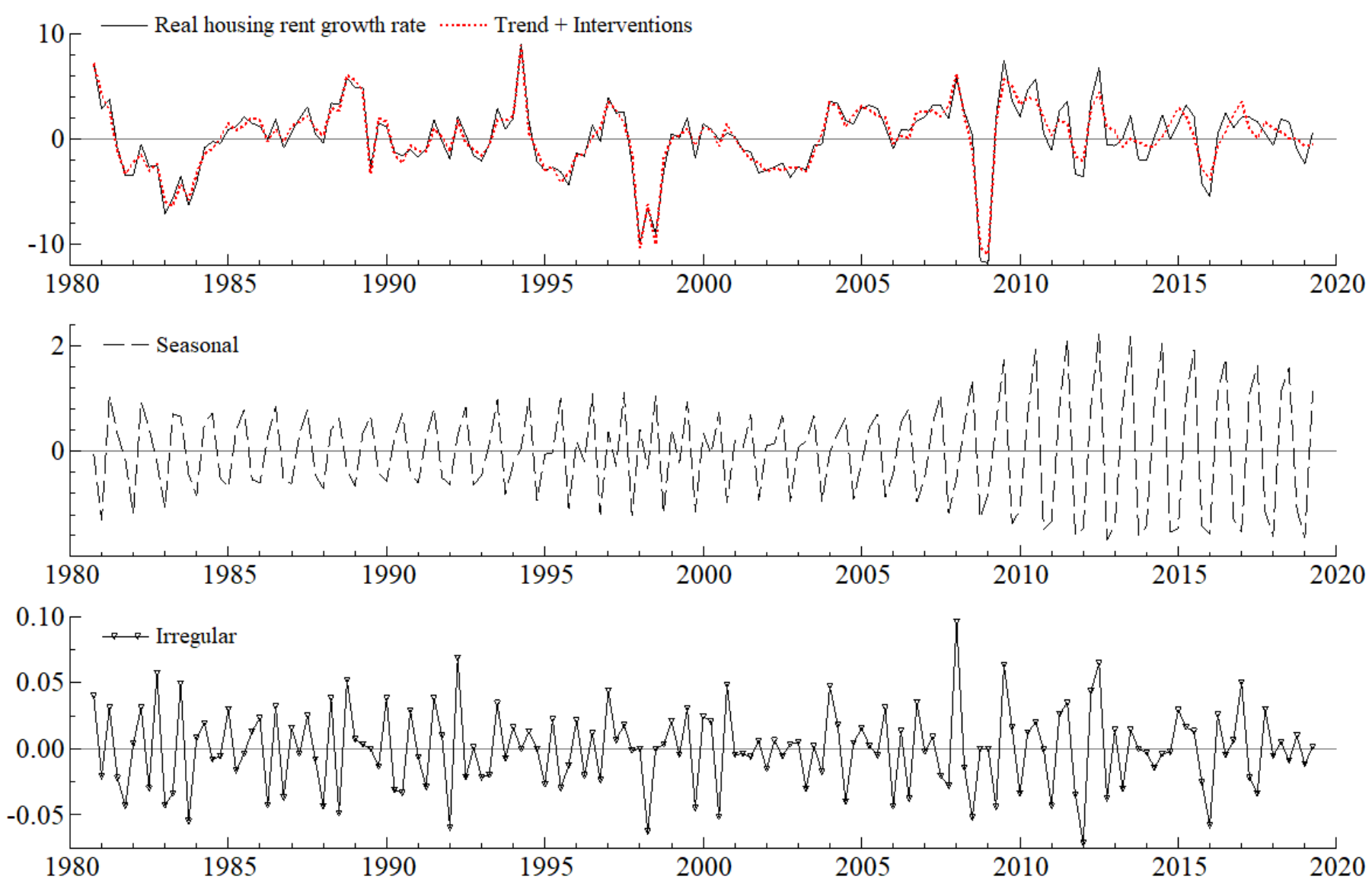